\title{
The effect of supply channel structures on remanufacturing, pricing, and acquisition management
}

\author{
Alireza Taheri-Moghadam*, Fariborz Jolai, Jafar Razmi and Ata Allah Taleizadeh \\ School of Industrial Engineering, College of Engineering, University of Tehran, Iran \\ *Corresponding Author : taherimoghadam@ut.ac.ir
}

Submitted :03/01/2020

Revised : :11/12/2020

Accepted : 20/02/2021

\begin{abstract}
This paper developed an acquisition management problem in a Closed-Loop Supply chain (CLSC) network. This study determines optimal selling prices of brand-new and remanufactured products, wholesale prices, and acquisition prices in various distribution and collection channel structures. It shows that determining the best structure is highly affected by the model's parameters, as well as the decision-makers' objectives. Moreover, precious managerial insights from five different viewpoints have been provided for decision-makers in order to benefit considerably from various situations of remanufacturing and acquisition activities, as well as manufacturing and distribution activities. Simulation approach is employed for analyzing the proposed solutions in different conditions.
\end{abstract}

Keywords: Closed-loop supply chain; Collection channels; Distribution channels; Game theory; Product return.

\section{INTRODUCTION}

Remanufacturing a product usually saves about $40 \%$ to $60 \%$ of manufacturing costs and $85 \%$ of energy consumption in comparison to manufacturing a brand-new product (Chen and Chang 2012b). Annually, retailers return over $\$ 100$ billion used products from customers, while $35 \%$ of products are returned before the end of their life cycle (Vorasayan and Ryan 2006). Therefore, the reverse flow of the supply chains and CLSC is encouraging enough to merit future investigation.

Several industries such as automobiles, electronics, and games, and generally the companies who produce short life cycle products, have great demand for remanufactured, second-hand, and repaired products (S.-S. Gan et al. 2017). For example, some of the automobile and electronics companies such as Toyota, Tesla, HP, Dell, and Apple developed new approaches to reuse and recycle spare-parts and materials and they are taking full advantage of their reuse/ recycle programs (He 2015). Atasu et al. (2008) represents successful remanufacturing systems of some pioneer companies such as Mercedes-Benz, IBM, DEC, and Xerox.

There are various techniques for acquisition management. Jena and Sarmah (2016) reviewed the researches in the field of acquisition management. They mention that manufacturers use price incentives to return used products.

Various assumptions have been made through different models for returning used products from customers, the (re)manufacturer can collect used products directly or indirectly i.e. through a retailer or outsourcing the returning 
activities. In addition, several choices have been considered for the returned products, i.e. reusing, repairing, remanufacturing, recovering, recycling, disposal, etc. (Jena and Sarmah 2016).

However, there are still several questions that need to be answered by the researchers. This article intends to discuss the answers to the following questions:

- How do the selling prices of remanufactured products, brand-new products, and

- $\quad$ acquisition prices interact with each other?

- How do the distribution and collection channels' structures affect modeling and profits of the supply chain members?

- Which structures provide more profit for the supply chain members?

- Which configurations lead to less selling price or higher acquisition price for customers?

- How do the governments can benefit from distribution and collection channels' structures in order to improve remanufacturing activities?

\section{LITERATURE REVIEW}

Most of the previous researches assume that the remanufactured and brand-new products are identical to the market and they have similar selling prices (Mitra 2016). Although assuming the lower price for remanufactured products may cannibalize market share of brand-new products in some circumstances, it does not provide consumers' satisfaction. Remanufactured products are more economical for consumers, and the manufacturers can widen their market by satisfying the consumers who are not willing to pay full price for a brand-new product. In addition, since the remanufacturing cost is usually lower than manufacturing cost, there are more profit margins for remanufactured products, and the firms can determine the selling price of remanufactured products cheaper than the brand-new products in order to achieve higher market share in competitive markets and maximize their profit (L. Zhou et al., 2017).

Guide and Li (2010) investigated consumers' willingness to pay for brand-new and remanufactured products. They show that, for remanufactured products, the consumers' willingness to pay is $15.3 \%$ less than that for brandnew products, which implies that the sales of brand-new products are not cannibalized by the remanufactured products. Xerox managers firmly believe that remanufactured and brand-new products do not compete in the same fixed market, but the remanufactured products with the lower price make them reach extra market segments that will not be satisfied by more expensive brand-new products. Besides, there are always various options for forward and reverse flows of the CLSC, while most of the researchers consider a limited number of supply channels, moreover, most of the articles related to the acquisition management literature, consider a pure remanufacturing system (Cai et al. 2014).

Table 1 represents the most important related researches that provide mathematical models in the fields of remanufacturing, product cannibalization, acquisition management, and pricing problems, in order to clarify research gaps and contributions of our work.

Table 1 clarifies that, although some of the previous articles have investigated different prices between brandnew and remanufactured products, they do not as yet go into the optimization of acquisition price and consideration of decentralized conditions. 


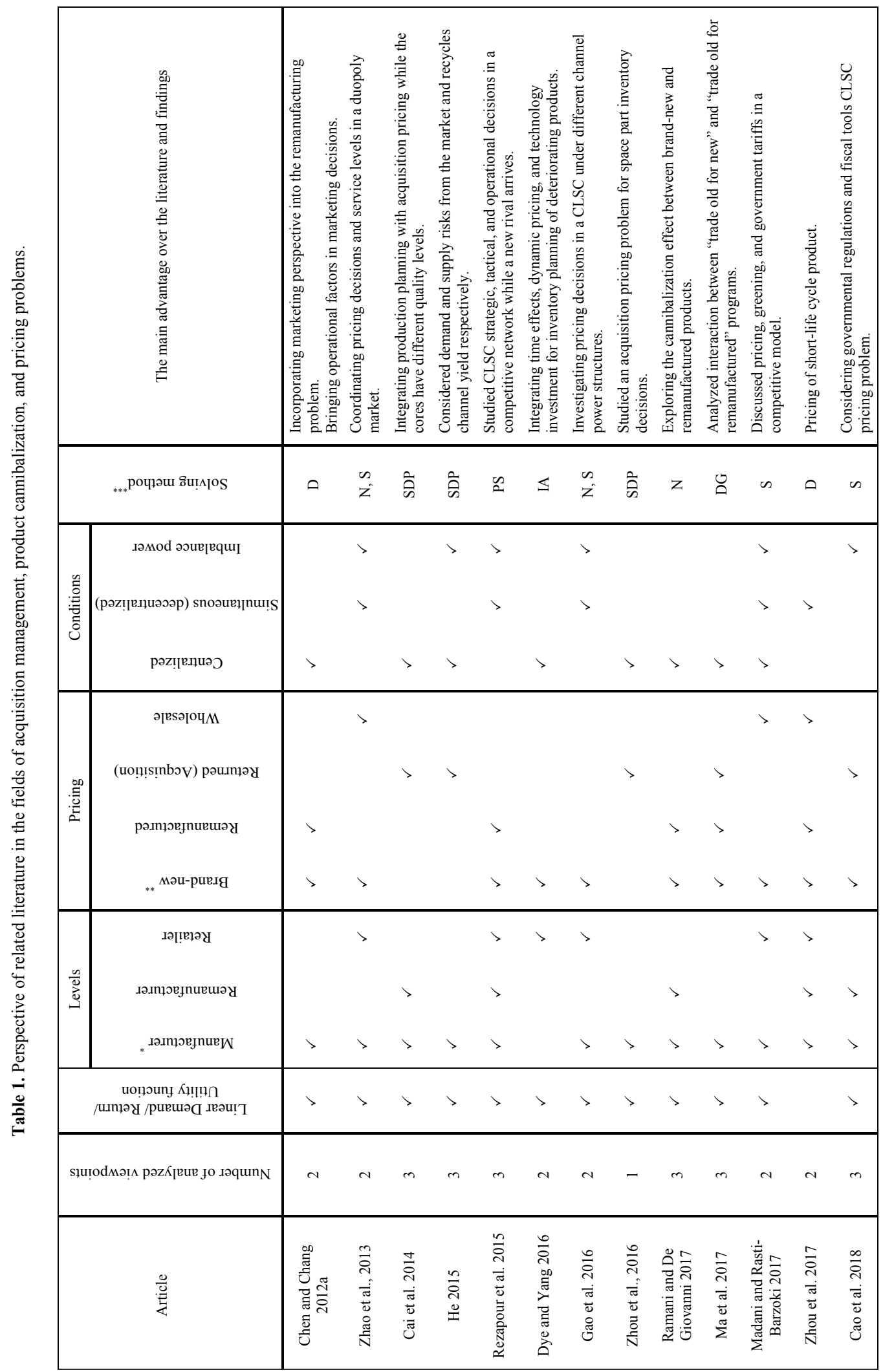




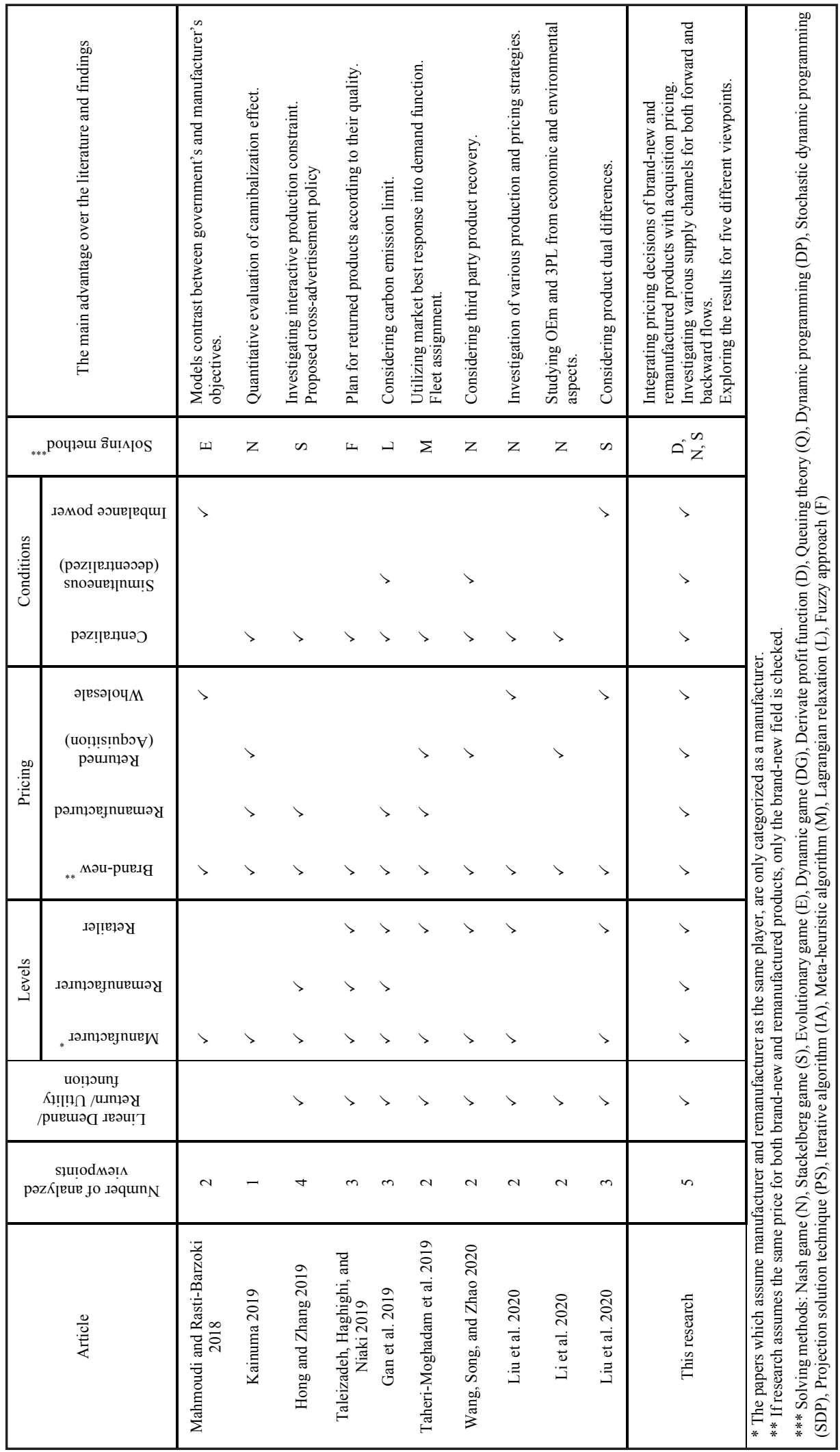


This paper explores the most common supply channels in CLSC network. The results clarify that in some cases, integration of the activities satisfies only the manufacturer and it cannot guarantee the best-selling prices (customer satisfaction), or the number of remanufactured products (sustainability). In other words, in some cases, competitive situations or decentralized conditions may provide higher environmental protection level (increase quantity of remanufactured products), or higher customer satisfaction level (decrease selling prices) than the centralized condition.

This paper makes at least three important contributions. Firstly, to the best of our knowledge, this paper is the first study that considers pricing decisions for brand-new products, remanufactured products, and acquisition pricing, while brand-new and remanufactured products are distinguished in the market. Please note that, as it is explained, previous researchers rarely have distinguished the price of brand-new and remanufactured products such as Zhou et al. (2017), besides, some of the previous researchers have considered pricing and acquisition problems as an integrated model such as Ma et al. (2017) and Cao et al. (2018). But none of them investigates the integrated models, while the brand-new and remanufactured products are distinguished.

Secondly, this paper explores the most common supply channel structures. It investigates several structures in order to cover various situations that may occur in a practical environment which expands the application of the proposed models.

Finally, this paper provides precious managerial insights in order to benefit considerably from various situations. Exploring the various supply chain structures, leadership, and contracts can help managers to choose a proper structure (Guo et al. 2017). We provide managerial insights of five viewpoints: 1- Manufacturer, 2- Remanufacturer, 3- Retailer, 4- Customer, 5- Government (environment/social protection).

\section{MODELS DEFINITIONS}

In this study, a manufacturing-remanufacturing CLSC network is investigated by four different distribution channel structures that cover the most common combinations of CLSC channel structures. Manufacturing and remanufacturing activities can be centralized or decentralized (Miao et al. 2017). In addition, in decentralized form, manufacturer, remanufacturer, and retailer may compete or cooperate with each other. Moreover, manufacturer, remanufacturer or retailer (third party logistics) may handle acquisition management and/or retailing activities.

The first structure explores centralized condition, the second structure handles decentralized condition, the third structure assumes that the flow of returned products passes through the retailer as well as the forward flow, and the fourth structure investigates a condition in which there are a manufacturer and a remanufacturer in a competitive CLSC network. Table 2 illustrates the proposed structures and their decision variables.

Table 2. The proposed structures.

\begin{tabular}{|c|c|c|c|c|}
\hline \multirow{2}{*}{ Structure } & \multicolumn{3}{|c|}{ Decision variables } & \multirow{2}{*}{ Solving approach } \\
\hline & Manufacturer & Remanufacturer & Retailer & \\
\hline 1 & $p_{n}, p_{r}, A_{c}$ & - & - & Nash equilibrium \\
\hline
\end{tabular}


2

3

$$
w_{n}, w_{r}, A_{r}
$$

4

$$
w_{n}, w_{r}, A_{c}
$$

$$
p_{n} \quad p_{r}, A_{c}
$$

$p_{n}, p_{r} \quad$ Stackelberg game (Manufacturer as leader)

$p_{n}, p_{r}, A_{c} \quad$ Stackelberg game (Manufacturer as leader)

Nash equilibrium

Stackelberg game (Manufacturer as leader)

Stackelberg game (Remanufacturer as leader)

\section{Parameters}

Parameters of the mathematical models are defined as follows:

$\mathrm{c}_{\mathrm{m}} \quad$ Manufacturing cost for a unit of brand-new product (including raw material cost too).

$c_{\mathrm{r}} \quad$ Remanufacturing cost per unit of remanufactured product (including material cost too).

$c_{t} \quad$ Retail cost per unit of product (including all costs of the retailer such as warehousing, transportation, advertisement, fixed costs, etc.)

$a_{n} \quad$ Market size for brand-new products i.e. if the selling price of all products are set to 0 , total demand will be equal to $a_{n}$

ar $\quad$ Market size for remanufactured products (it is determined similar to $a_{n}$ )

$\alpha p \quad$ Coefficient of self-price demand sensitivity of a product $(p \in\{n, r\})$

$\beta p \quad$ Coefficient of demand sensitivity to other products (alternative products) price $(p \in\{n, r\})$

b Minimum number of retuned products

$\lambda \quad$ Coefficient of return sensitivity to the acquisition price

$\mathrm{RP} 1 \quad$ Minimum profit per unit of product that the retailer expects for distribution activities

$\mathrm{RP}_{2} \quad$ Retailer's minimum profit for returning a unit of used product

\section{Variables}

Decision variables of the models are defined as follows:

$\mathrm{W}_{\mathrm{n}} \quad$ Wholesale price per unit of a brand-new product

$\mathrm{W}_{\mathrm{r}} \quad$ Wholesale price per unit of remanufactured product

$\mathrm{p}_{\mathrm{n}} \quad$ Retail price per unit of a brand-new product

$\mathrm{p}_{\mathrm{r}} \quad$ Retail price per unit of remanufactured product

$\mathrm{A}_{\mathrm{c}} \quad$ Amount of money that customers get for a unit of retuned product

$\mathrm{A}_{\mathrm{r}} \quad$ Amount of money that the retailer gets for a unit of the returned product minus the acquisition

price that the retailer spends for acquiring a unit of product

Other variables of the models are defined as follows:

$D_{n} \quad$ The demand for the brand-new product

$\mathrm{D}_{\mathrm{r}} \quad$ The demand of the remanufactured product

$\mathrm{R} \quad$ Quantity of returned products

$\pi^{\mathrm{I}} \quad$ Profit of the whole CLSC in the first structure (centralized)

$\pi_{\mathrm{M}}{ }^{\mathrm{II}} \quad$ Profit of the manufacturer in the second structure (decentralized) 


$\begin{array}{ll}\pi_{R}{ }_{\mathrm{II}} & \text { Profit of the retailer in the second structure (decentralized) } \\ \pi_{\mathrm{M}}{ }_{\mathrm{M}} & \text { Profit of the manufacturer in the third structure } \\ \pi_{\mathrm{R}}{ }^{\mathrm{III}} & \text { Profit of the retailer in the third structure } \\ \pi_{\mathrm{M}}{ }_{\mathrm{IV}} & \text { Profit of the manufacturer in the fourth structure } \\ \pi_{\mathrm{RM}}{ }^{\mathrm{IV}} & \text { Profit of the remanufacturer in the fourth structure }\end{array}$

\section{Demand Function}

The researchers basically use two different approaches for modeling the relationship between demand and price: 1- direct demand function, that assumes the quantity of demand is a function of selling price, 2- inverse demand function, that assumes the selling price is a function of the quantity of demand (Madani and Rasti-Barzoki 2017). The direct demand function is utilized by this research.

Linear demand function with respect to pricing variables has been extensively established in various closedloop supply chain models, and several researchers claim that the linear demand function can be utilized properly in the CLSC networks. Besides, as Table 1 shows, almost all of the related researches have applied linear demand function for modeling similar mathematical models of the pricing problem, which indicates that the linear demand function has been utilized in various cases and the performance of it in modeling and solving such problem has been approved previously by several researchers. The linear demand function not only simplifies the mathematical models and their calculations, but also it can fit several practical cases such as Ramani and De Giovanni (2017) and Ovchinnikov (2011).

A market size $(a)$ is assumed for each product, which indicates the maximum demand when the selling prices are set to zero. Offering the brand-new product at price $p_{n}$ affects the demands of brand-new and remanufactured products by $-\alpha_{n} p_{n}$ and $+\beta_{n} p_{n}$ respectively. The selling price of the remanufactured product has a similar impact on the demand for itself and the replaceable product.

The utilized demand and return functions have been proposed by previous researchers such as (Madani and Rasti-Barzoki 2017; Zhou et al., 2016), which are presented by equations (1) to (3).

$$
\begin{aligned}
& D_{n}\left(p_{n}, p_{r}\right)=a_{n}-\alpha_{n} \times p_{n}+\beta_{n} \times p_{r} \\
& D_{r}\left(p_{n}, p_{r}\right)=a_{r}-\alpha_{r} \times p_{r}+\beta_{r} \times p_{n} \\
& R=b+\lambda \times A_{c}
\end{aligned}
$$

Please note that all of the parameters $\left(c_{m}, c_{r}, c_{t}, a_{n}, a_{r}, b, \alpha, \beta, \lambda>0\right)$, and profit margins are assumed as positive numbers. For example, we have $p_{r}-A_{c}-A_{r}-c_{r}-c_{t}>0$. In other words, products will be manufactured, remanufactured, or returned, unless it is unprofitable. Besides, it is assumed that the coefficient of self-price demand sensitivity of a product is always greater than the coefficient of demand sensitivity to alternative products' selling price $(\alpha>\beta)$.

These assumptions guarantee rationality of the models and concavity of the profit functions. 


\section{FORMULATION}

\section{The First Structure}

All of the supply chain activities are centralized in this model, and one centralized organization determines all of the decision variables, which is known as a manufacturer. Customers' behavior is estimated by demand and return functions (equations (1) to (3)). Please note that in the parametric solutions $\alpha_{n}$, and $\beta_{n}$, are assumed equal to $\alpha_{r}$, and $\beta_{r}$ respectively, in order to avoid over-complexity of equations. But, they can be different coefficients in numerical examples without increasing the complexity of the solution approach. The manufacturer intends to maximize total supply chain profit $\left(\pi^{I}\right)$ that is defined by equation (4).

$$
\begin{aligned}
\pi^{I}\left(p_{n}, p_{r}, A_{c}\right)= & D_{n}\left(p_{n}, p_{r}\right) \times\left(p_{n}-c_{m}-c_{t}\right) \\
& +\min \left(D_{r}\left(p_{n}, p_{r}\right), R\left(A_{c}\right)\right) \times\left(p_{r}-A_{c}-c_{r}-c_{t}\right)
\end{aligned}
$$

In which, the first term calculates total profit for selling brand-new products and the second term calculates total profit for selling remanufactured products. The amount of remanufactured products that can be sold is equal to the minimum demand $\left(D_{r}\right)$ and availability $(R)$ of that product. If the customers do not return their used products, the company is unable to remanufacture retuned products even if there is a great demand for them.

\section{Theorem 1.}

For the optimal solution, the demand for remanufactured products $D_{r}$ should be equal to returned products $(R)$, as equation (5) shows.

$$
\min \left(R\left(A_{c}^{*}\right), D_{r}\left({p_{n}}^{*}, p_{r}{ }^{*}\right)\right)=R\left(A_{c}^{*}\right)=D_{r}\left({p_{n}}^{*}, p_{r}{ }^{*}\right)
$$

Proof of Theorem 1 is presented by APPENDIX A.

By using Theorem 1, for optimal solutions, $A_{c}{ }^{*}$ can be calculated by equation (6), and the profit function (4) can be rewritten as equation (7).

$$
\begin{aligned}
R\left(A_{c}^{*}\right)=D_{r}\left(p_{n}^{*}, p_{r}{ }^{*}\right) \Rightarrow A_{c}{ }^{*}=\frac{a_{r}-\alpha \times p_{r}{ }^{*}+\beta \times p_{n}{ }^{*}-b}{\lambda} & \\
\pi^{I}\left(p_{n}{ }^{*}, p_{r}{ }^{*}\right) & =\left(a_{n}-\alpha \times p_{n}{ }^{*}+\beta \times p_{r}{ }^{*}\right) \times\left(p_{n}{ }^{*}-c_{m}-c_{t}\right) \\
& +\left(a_{r}-\alpha \times p_{r}{ }^{*}+\beta \times p_{n}{ }^{*}\right) \times\left(p_{r}{ }^{*}-c_{r}-c_{t}-\frac{a_{r}-\alpha \times p_{r}{ }^{*}+\beta \times p_{n}{ }^{*}-b}{\lambda}\right)
\end{aligned}
$$

The $\pi^{I}\left(p_{n}{ }^{*}, p_{r}{ }^{*}\right)$ is jointly concave function in $p_{n}{ }^{*}, p_{r}{ }^{*}$, as it is explained by APPENDIX B, and the maximum profit can be calculated by first orders derivatives as it is shown by APPENDIX C. Values of $p_{n}{ }^{*}$ and $p_{r}{ }^{*}$ are presented by equation (8), in which $K_{i}$ is defined just for simplifying the equations, and the formulation of them are presented by APPENDIX C. 


$$
\left\{\begin{array}{l}
p_{n}{ }^{*}=\left(K_{4} K_{3}-\frac{K_{1} K_{4} K_{5}}{K_{2}}\right)\left(\frac{1}{K_{2}^{2}-K_{1} K_{4}}\right)-\frac{K_{5}}{K_{2}} \\
p_{r}^{*}=\left(\frac{K_{1} K_{5}}{K_{2}}-K_{3}\right)\left(\frac{K_{2}}{K_{2}^{2}-K_{1} K_{4}}\right)
\end{array}\right.
$$

Please note that a centralized decision-maker can always make the same decisions as to the collection of decentralized decision-makers. Hence, the first structure always provides maximum profit for the whole supply chain in comparison with other models.

\section{The Second Structure}

This structure assumes that the manufacturer and the retailer decide independently and the manufacturer should handle acquisition management. Profit functions of the manufacturer and retailer are presented by equations (9) and (10) respectively. Please note that the profit function of the whole supply chain is equal to $\pi_{M}{ }^{I I}+\pi_{R}{ }^{I I}$ (from equations (9) and (10)), which is similar to $\pi^{I}$ (equation (4)).

Theorem 1 is used for relaxing $p_{r}{ }^{*}$ by $p_{n}{ }^{*}$, and $A_{c}{ }^{*}$. Equations (11) to (13) present the relaxed form of profit functions. Please note that Theorem 1 is proven just for the optimal solution and the relaxed form is true for the optimum point and it can be true or false for other solutions. The optimal values of the decision variables are presented by equations (14) to (18).

The calculations are explained in APPENDIX C.

$$
\begin{aligned}
& \pi_{M}^{I I}\left(w_{n}, w_{r}, A_{c}\right)=D_{n}\left(p_{n}, p_{r}\right) \times\left(w_{n}-c_{m}\right)+\min \left\{\begin{array}{l}
D_{r}\left(p_{n}, p_{r}\right) \\
R\left(A_{c}\right)
\end{array}\right\} \times\left(w_{r}-A_{c}-c_{r}\right) \\
& \pi_{R}^{I I}\left(p_{n}, p_{r}\right)=D_{n}\left(p_{n}, p_{r}\right) \times\left(p_{n}-w_{n}-c_{t}\right)+\min \left\{\begin{array}{l}
D_{r}\left(p_{n}, p_{r}\right) \\
R\left(A_{c}\right)
\end{array}\right\} \times\left(p_{r}-w_{r}-c_{t}\right) \\
& \pi_{M}{ }^{I I}\left(w_{n}^{*}, w_{r}^{*}, A_{c}^{*}\right)=D_{n}\left(p_{n}^{*}, p_{r}^{*}\right) \times\left(w_{n}^{*}-c_{m}\right)+R\left(A_{c}^{*}\right) \times\left(w_{r}^{*}-A_{c}^{*}-c_{r}\right) \\
& \pi_{R}^{I I}\left(p_{n}^{*}, p_{r}^{*}\right)=D_{n}\left(p_{n}^{*}, p_{r}^{*}\right) \times\left(p_{n}^{*}-w_{n}^{*}-c_{t}\right)+R\left(A_{c}^{*}\right) \times\left(p_{r}^{*}-w_{r}{ }^{*}-c_{t}\right) \\
& p_{r}^{*}=\frac{\beta p_{n}^{*}-\lambda A_{c}^{*}+a_{r}-b}{\alpha} \\
& p_{n}^{*}\left(w_{n}^{*}\right)=\frac{\left(w_{n}^{*}+c_{t}\right)}{2}+\frac{\alpha a_{n}+\beta a_{r}}{2\left(\alpha^{2}-\beta^{2}\right)}
\end{aligned}
$$


$p_{r}{ }^{*}\left(w_{n}{ }^{*}, A_{c}^{*}\right)=\frac{\beta\left(w_{n}{ }^{*}+c_{t}\right)}{2 \alpha}+\frac{\beta\left(\alpha a_{n}+\beta a_{r}\right)}{2 \alpha\left(\alpha^{2}-\beta^{2}\right)}+\frac{a_{r}-\lambda A_{c}^{*}-b}{\alpha}$
$A_{c}^{*}\left(w_{r}^{*}, w_{n}^{*}\right)=\frac{w_{r}^{*}-c_{r}-\frac{\beta}{\alpha}\left(w_{n}{ }^{*}-c_{m}\right)-\frac{b}{\lambda}}{2}$
$w_{n}^{*}\left(A_{c}^{*}\right)=\frac{c_{m}-c_{t}}{2}+\frac{\frac{\beta}{\alpha}\left(a_{r}-\lambda A_{c}^{*}-b\right)+a_{n}-\frac{\alpha a_{n}+\beta a_{r}}{2 \alpha}}{\alpha^{2}-\beta^{2}}$
$w_{r}^{*}\left(w_{n}{ }^{*}, A_{c}^{*}\right)=\frac{\beta\left(w_{n}{ }^{*}+c_{t}\right)}{2 \alpha}+\frac{\beta\left(\alpha a_{n}+\beta a_{r}\right)}{2 \alpha\left(\alpha^{2}-\beta^{2}\right)}+\frac{a_{r}-\lambda A_{c}^{*}-b}{\alpha}-c_{t}-R P_{1}$

Please note that the above equations do not guarantee the retailer's constraint for distribution profit of brandnew products, and such circumstances should be surveyed. If the retailer is not satisfied, the manufacturer may accept or refuse the retailer's condition. Clearly, the second option indicates that the game is over, and the total profit is equal to zero.

Hence, only the first option is surveyed here. This infeasible circumstance indicates that the profit of the retailer to distribute a unit of brand-new product is not enough $\left(p_{n}{ }^{*}-w_{n}{ }^{*}-c_{t}<\right.$

$\left.R P_{l}\right)$.

The Condition Of $\mathrm{p}_{\mathrm{n}}{ }^{*}-\mathrm{w}_{\mathrm{n}}{ }^{*}-\mathrm{c}_{\mathrm{t}}<\mathrm{RP}_{1}$

The optimal values of the decision variables in such conditions are determined by equations

(19) to (23). The formulations of $K_{i}$ are presented in APPENDIX C.

$$
\begin{aligned}
& p_{n}{ }^{*}=w_{n}{ }^{*}+c_{t}+R P_{1} \\
& p_{r}^{*}=\frac{a_{r}+\beta\left(w_{n}{ }^{*}+c_{t}+R P_{1}\right)-b-\lambda A_{c}^{*}}{\alpha} \\
& w_{r}^{*}=\frac{2 \beta-\lambda}{2(\alpha+\beta)} w_{n}^{*}+K_{6} \\
& A_{c}^{*}=\left(\frac{2 \beta-\lambda}{4(\alpha+\beta)}-\frac{\beta}{2 \alpha}\right) w_{n}{ }^{*}+K_{7}
\end{aligned}
$$




$$
w_{n}^{*}=\frac{\left(\begin{array}{l}
\frac{\beta c_{m}}{\alpha}\left(\frac{\beta^{2}-\alpha}{\beta}-\frac{\lambda(2 \beta-\lambda)}{4(\alpha+\beta)}+\frac{\beta \lambda}{2 \alpha}\right)+\frac{\beta \lambda K_{7}}{\alpha}-K_{8}+\frac{\lambda\left(K_{7}+c_{r}-K_{6}\right)}{2}\left(\frac{2 \beta-\lambda}{2(\alpha+\beta)}-\frac{\beta}{\alpha}\right) \\
-\frac{\left(b+\lambda K_{7}\right)(2 \beta-\lambda)}{4(\alpha+\beta)}
\end{array}\right)}{\frac{2 \beta}{\alpha}\left(\frac{\beta^{2}-\alpha}{\beta}-\frac{\lambda(2 \beta-\lambda)}{4(\alpha+\beta)}+\frac{\beta \lambda}{2 \alpha}\right)+\lambda\left(\frac{2 \beta-\lambda}{2(\alpha+\beta)}-\frac{\beta}{\alpha}\right)\left(\frac{2 \beta-\lambda}{4(\alpha+\beta)}+\frac{\beta}{2 \alpha}\right)}
$$

\section{The Third Structure}

This structure assumes that the retailer handles acquisition management. Profit functions for both of the manufacturer and the retailer are presented by equations (24) and (25). The optimal values of the decision variables are determined by equations (26) to (30).

$$
\begin{aligned}
& \pi_{M}^{I I I}\left(w_{n}, w_{r}, A_{r}\right)=D_{n}\left(p_{n}, p_{r}\right) \times\left(w_{n}-c_{m}\right)+\min \left\{\begin{array}{l}
D_{r}\left(p_{n}, p_{r}\right) \\
R\left(A_{c}\right)
\end{array}\right\} \times\left(w_{r}-A_{r}-A_{c}-c_{r}\right) \\
& \pi_{R}{ }^{I I I}\left(p_{n}, p_{r}, A_{c}\right)=D_{n}\left(p_{n}, p_{r}\right) \times\left(p_{n}-w_{n}-c_{t}\right)+\min \left\{\begin{array}{l}
D_{r}\left(p_{n}, p_{r}\right) \\
R\left(A_{c}\right)
\end{array}\right\} \times\left(p_{r}+A_{r}-w_{r}-c_{t}\right) \\
& A_{c}^{*}=\frac{a_{r}-\alpha p_{r}{ }^{*}+\beta p_{n}{ }^{*}-b}{\lambda} \\
& p_{n}^{*}\left(w_{n}^{*}\right)=\frac{\left(\alpha^{2}-\beta\right)\left(w_{n}{ }^{*}+c_{t}\right)+\alpha a_{n}+\beta a_{r}}{2 \alpha^{2}-\beta(1+\beta)} \\
& p_{r}^{*}\left(w_{n}^{*}, w_{r}^{*}, A_{r}^{*}\right)=\frac{A_{r}^{*}+w_{r}^{*}+c_{t}}{2}+\frac{(\beta-1)\left(w_{n}^{*}+c_{t}\right)+2 \alpha a_{r}+(1+\beta) a_{n}}{4 \alpha^{2}-2 \beta(1+\beta)} \\
& A_{r}^{*}=R P_{2}
\end{aligned}
$$




$$
\left\{\begin{array}{r}
\left(\frac{\beta}{2}\right) w_{r}{ }^{*}+\left(\frac{\beta}{2}\right) R P_{2}+K_{16}-A_{1} c_{m}+K_{17}\left(\left(1+\frac{\alpha}{2 \lambda}\right) w_{r}{ }^{*}-R P_{2}-\frac{K_{18}-b}{\lambda}-c_{r}\right) \\
+\frac{K_{17}}{\lambda}\left(\left(\frac{\alpha}{2}\right) w_{r}{ }^{*}+\left(\frac{\alpha}{2}\right) R P_{2}-K_{18}\right)+\left(2 K_{15}-\frac{2 K_{17}{ }^{2}}{\lambda}\right) w_{n}{ }^{*}=0 \\
\frac{\beta}{2}\left(w_{n}{ }^{*}-c_{m}\right)+\left(1+\frac{\alpha}{2 \lambda}\right)\left(K_{17} w_{n}{ }^{*}-\left(\frac{\alpha}{2}\right) R P_{2}+K_{18}\right) \\
+\frac{\alpha}{2}\left(R P_{2}+\frac{K_{17} w_{n}{ }^{*}+K_{18}-b}{\lambda}+c_{r}\right)-\alpha\left(1+\frac{\alpha}{2 \lambda}\right) w_{r}{ }^{*}=0
\end{array}\right.
$$

The above equations may not satisfy the retailer's minimum profit to distribute a unit of product and they may lead to an infeasible circumstance, which makes the manufacturer accept or refuse the retailer's conditions. Clearly, the case of rejection leads to zero profit, and we just study the acceptance option.

There are three different conditions for these infeasible circumstances: $1-p_{n}{ }^{*}-w_{n}{ }^{*}-c_{t}<R P_{1} ; 2-p_{r}{ }^{*}-w_{r}{ }^{*}-c_{t}<R P_{l}$; 3- $p_{n}{ }^{*}-w_{n}{ }^{*}-c_{t}<R P_{l}$ while $p_{r}{ }^{*}-w_{r}{ }^{*}-c_{t}<R P_{l}$. All of the mentioned conditions are studied briefly in the following. The calculations of $K_{i}$ are presented in APPENDIX C.

Please note that the manufacturer is considered as the leader, hence, there is no need for assuming a similar constraint for the manufacturer's profit. Clearly, if the manufacturer does not benefit enough, the manufacturerretailer game will be over, and the manufacturer will not outsource retailing activities, and other structures should be considered instead, i.e. first and fourth structures.

The Condition Of $\mathrm{pn}^{*}$ - wn*- ct $<$ RP1

The optimal values of the decision variables in such conditions are determined by equations (31) to (35).

$$
\begin{aligned}
& p_{n}{ }^{*}=w_{n}{ }^{*}+c_{t}+R P_{1} \\
& A_{c}{ }^{*}=\frac{a_{r}-\alpha p_{r}{ }^{*}+\beta p_{n}{ }^{*}-b}{\lambda} \\
& A_{r}{ }^{*}=R P_{2} \\
& p_{r}{ }^{*}=\frac{\beta w_{n}{ }^{*}+\alpha w_{r}{ }^{*}-\alpha A_{r}{ }^{*}+2 \beta R P_{1}+a_{r}+\alpha c_{r}+\beta c_{t}}{2 \alpha} \\
& \left\{\begin{array}{l}
\left(\frac{\beta^{2}-2 \alpha^{2}}{\alpha}-\frac{\beta^{2}}{2 \lambda}\right) w_{n}{ }^{*}+\left(1+\frac{\alpha}{\lambda}\right) w_{r}{ }^{*}+K_{19}-\frac{\beta^{2}-2 \alpha^{2}}{2 \alpha} c_{m}+\frac{\beta K_{21}}{2}-\frac{\beta K_{20}}{2 \lambda}=0 \\
\left(\beta+\frac{\alpha \beta}{2 \lambda}\right) w_{n}{ }^{*}-\alpha\left(1+\frac{\alpha}{2 \lambda}\right) w_{r}{ }^{*}+-\frac{\beta c_{m}}{2}-\frac{\alpha K_{21}}{2}+\left(1+\frac{\alpha}{2 \lambda}\right) K_{20}=0
\end{array}\right.
\end{aligned}
$$


The Condition Of $p_{r}{ }^{*}-w_{r}{ }^{*}-c_{t}<R P_{1}$

The optimal values of the decision variables in such conditions are determined by equations (36) to (40).

$$
\begin{aligned}
& p_{r}{ }^{*}=w_{r}{ }^{*}+c_{t}+R P_{1} \\
& A_{c}^{*}=\frac{a_{r}-\alpha p_{r}^{*}+\beta p_{n}^{*}-b}{\lambda} \\
& A_{r}^{*}=R P_{2} \\
& p_{n}^{*}=\frac{w_{n}^{*}}{2}+\frac{\beta w_{r}^{*}}{2 \alpha}+\frac{\beta A_{r}^{*}}{2 \alpha}+\frac{a_{n}+2 \beta\left(R P_{1}+c_{t}\right)-\beta c_{t}+\alpha c_{t}}{2 \alpha} \\
& -\left(\alpha+\frac{\beta^{2}}{2 \lambda}\right) w_{n}{ }^{*}+\beta\left(1-\frac{\beta^{2}-2 \alpha^{2}}{2 \alpha \lambda}\right) w_{r}{ }^{*}+K_{22}+\frac{\alpha c_{m}+\beta K_{23}-\frac{\beta}{\lambda} K_{24}}{2}=0 \\
& \left(1-\frac{\beta^{2}-2 \alpha^{2}}{2 \alpha \lambda}\right) w_{n}{ }^{*}+\left(1-\frac{\beta^{2}-2 \alpha^{2}}{2 \alpha \lambda}\right)\left(\frac{\beta^{2}-2 \alpha^{2}}{\alpha}\right) w_{r}{ }^{*}-\frac{\beta c_{m}}{2}+ \\
& +\left(1-\frac{\beta^{2}-2 \alpha^{2}}{2 \alpha \lambda}\right) K_{24}+\left(\frac{\beta^{2}-2 \alpha^{2}}{2 \alpha}\right) K_{23}=0
\end{aligned}
$$

The Condition Of $p_{n}{ }^{*}-w_{n}{ }^{*}-c_{t}<R P_{1}$ While $p_{r}{ }^{*}-w_{r}{ }^{*}-c_{t}<R P_{1}$

The optimal values of the decision variables in such conditions are determined by equations (41) to (45).

$$
\begin{aligned}
& p_{n}{ }^{*}=w_{n}{ }^{*}+c_{t}+R P_{1} \\
& p_{r}{ }^{*}=w_{r}{ }^{*}+c_{t}+R P_{1} \\
& A_{c}^{*}=\frac{a_{r}-\alpha p_{r}{ }^{*}+\beta p_{n}{ }^{*}-b}{\lambda} \\
& A_{r}{ }^{*}=R P_{2}
\end{aligned}
$$




$$
\left\{\begin{array}{l}
-2\left(\alpha+\frac{\beta^{2}}{\lambda}\right) w_{n}{ }^{*}+2 \beta\left(1+\frac{\alpha}{\lambda}\right) w_{r}{ }^{*}+K_{25}+\alpha c_{m}+\beta K_{27}-\frac{\beta K_{26}}{\lambda}=0 \\
2 \beta\left(1+\frac{\alpha}{\lambda}\right) w_{n}{ }^{*}-2 \alpha\left(1+\frac{\alpha}{\lambda}\right) w_{r}{ }^{*}-\beta c_{m}-\alpha K_{27}+\left(1+\frac{\alpha}{\lambda}\right) K_{26}=0
\end{array}\right.
$$

\section{The Fourth Structure}

This structure has two supply channels. The manufacturer handles only brand-new products and the remanufacturer handles acquisition management as well as remanufacturing activities. These two channels interact with each other. The manufacturer and the remanufacturer may compete (equal or different decision powers) or cooperate. The cooperation condition is the same as the centralized model (MCM), in which, they are assumed as the same player and they are intended to maximize overall profit. Profit functions for both of the manufacturer and the remanufacturer are presented by equations (46) and (47). Decision variables and profit function of the retailer can be relaxed by Theorem 1, as equations (48) and (49) show.

$$
\begin{aligned}
& \pi_{M}{ }^{I V}\left(p_{n}\right)=D_{n}\left(p_{n}, p_{r}\right) \times\left(p_{n}-c_{m}-c_{t}\right) \\
& \pi_{R M}{ }^{I V}\left(p_{r}, A_{c}\right)=\min \left\{\begin{array}{l}
D_{r}\left(p_{n}, p_{r}\right) \\
R\left(A_{c}\right)
\end{array}\right\} \times\left(p_{r}-A_{c}-c_{r}-c_{t}\right) \\
& \pi_{R M}{ }^{I V}\left(p_{r}^{*}, A_{c}^{*}\right)=D_{r}\left(p_{n}^{*}, p_{r}^{*}\right) \times\left(p_{r}^{*}-A_{c}^{*}-c_{r}-c_{t}\right) \\
& A_{c}^{*}=\frac{a_{r}-\alpha p_{r}{ }^{*}+\beta p_{n}{ }^{*}-b}{\lambda}
\end{aligned}
$$

\section{Nash Equilibrium}

If the manufacturer and the remanufacturer decide simultaneously, the Nash equilibrium is the most common method for determining the equilibrium situation (Barron 2013). The Nash equilibrium is determined by equations (50), (51), and (49).

$$
\begin{aligned}
& p_{n}{ }^{*}=\frac{a_{n}+\alpha\left(c_{m}+c_{t}\right)}{2 \alpha}+\frac{\left(\beta+\frac{2 \alpha \beta}{\lambda}\right)\left(\frac{a_{n}+\alpha\left(c_{m}+c_{t}\right)}{2 \alpha}\right)+\left(1+\frac{2 \alpha}{\lambda}\right) a_{r}+\alpha\left(c_{r}+c_{t}-\frac{b}{\lambda}\right)}{\frac{4 \alpha^{2}}{\beta}\left(1+\frac{\alpha}{\lambda}\right)-2 \alpha \beta\left(\frac{1}{2 \alpha}+\frac{1}{\lambda}\right)} \\
& p_{r}{ }^{*}=\frac{\left(\beta+\frac{2 \alpha \beta}{\lambda}\right)\left(\frac{a_{n}+\alpha\left(c_{m}+c_{t}\right)}{2 \alpha}\right)+\left(1+\frac{2 \alpha}{\lambda}\right) a_{r}+\alpha\left(c_{r}+c_{t}-\frac{b}{\lambda}\right)}{2 \alpha\left(1+\frac{\alpha}{\lambda}\right)-\beta^{2}\left(\frac{1}{2 \alpha}+\frac{1}{\lambda}\right)}
\end{aligned}
$$




\section{Manufacturer Leader}

The optimal solution of such condition is presented by equations (52), (53), and (49).

$$
\begin{aligned}
& p_{r}{ }^{*}\left(p_{n}{ }^{*}\right)=\frac{\left(\beta+\frac{2 \alpha \beta}{\lambda}\right) p_{n}{ }^{*}+\left(1+\frac{2 \alpha}{\lambda}\right) a_{r}+\alpha\left(c_{r}+c_{t}-\frac{b}{\lambda}\right)}{2 \alpha\left(1+\frac{\alpha}{\lambda}\right)} \\
& p_{n}{ }^{*}=\frac{2 \alpha a_{n}\left(1+\frac{\alpha}{\lambda}\right)+\beta a_{r}\left(1+\frac{2 \alpha}{\lambda}\right)+\alpha\left(c_{r}+c_{t}-\frac{b}{\lambda}\right)-\left(\beta^{2}+\frac{2 \alpha \beta^{2}}{\lambda}\right)\left(c_{m}+c_{t}\right)}{4 \alpha^{2}\left(1+\frac{\alpha}{\lambda}\right)-\left(\beta^{2}+\frac{2 \alpha \beta^{2}}{\lambda}\right)}
\end{aligned}
$$

\section{Remanufacturer Leader}

The optimal solution of such condition is presented by equations (54), (55), and (49).

$$
\begin{aligned}
& p_{n}{ }^{*}\left(p_{r}{ }^{*}\right)=\frac{a_{n}+\beta p_{r}{ }^{*}+\alpha\left(c_{m}+c_{t}\right)}{2 \alpha} \\
& p_{r}{ }^{*}=\frac{\left(\begin{array}{l}
\frac{\beta^{2}-2 \alpha^{2}}{2 \alpha}\left(\frac{a_{r}-b}{\lambda}+\frac{\beta a_{n}+\alpha \beta\left(c_{m}+c_{t}\right)}{2 \alpha \lambda}+c_{r}+c_{t}\right) \\
-\frac{2 \alpha \lambda+2 \alpha^{2}-\beta^{2}}{2 \alpha \lambda}\left(a_{r}+\frac{\beta a_{n}+\alpha \beta\left(c_{m}+c_{t}\right)}{2 \alpha}\right)
\end{array}\right)}{\left(\frac{\left(\beta^{2}-2 \alpha^{2}\right)\left(2 \alpha \lambda+2 \alpha^{2}-\beta^{2}\right)}{\alpha^{2} \lambda}\right)}
\end{aligned}
$$

All of the proposed models are solved parametrically, but the results cannot be analyzed in the parametric form, because there is no evidence which proves that a model always provides greater profit than the others (except the centralized model). Simulation study is implemented in order to analyze the behavior of the models and their results statistically.

\section{SIMULATION STUDY}

This section establishes the simulation study to analyze and investigate the behavior of the proposed models. The parameters are generated similar to practical environments. Studying historical data of three manufacturers in diary, electronics, and fashion industries show that parameters of remanufactured products such as cost and market size are usually $50 \%$ to $70 \%$ less than similar parameters for brand-new products. The other parameters are generated according to constraints of the mathematical model in order to avoid infeasibility of test problems. Table 3 , shows the random distributions to generate parameters of the test problems. 
Table 3. Statistical distribution of parameters for numerical simulations.

\begin{tabular}{|c|c|c|c|c|c|c|c|c|}
\hline Parameter & $c_{m}$ & $c_{r}$ & \multicolumn{3}{|c|}{$c_{t}$} & $b$ & \multicolumn{2}{|r|}{$a_{r}$} \\
\hline Distribution & $\mathrm{U}(10,20)$ & \multicolumn{2}{|c|}{$c_{m} \times \mathrm{U}(0.3,0.5)$} & \multicolumn{2}{|c|}{$c_{r} \times \mathrm{U}(0.3,0.5)$} & \multicolumn{2}{|c|}{$a_{n} \times \mathrm{U}(0,0.1)$} & $a_{n} \times \mathrm{U}(0.3,0.5)$ \\
\hline Parameter & $a_{n}$ & $\alpha$ & $\beta$ & & $\lambda$ & & $\boldsymbol{R} P_{1}$ & $\boldsymbol{R} \boldsymbol{P}_{2}$ \\
\hline Distribution & $\mathrm{U}(500,600)$ & $\mathrm{U}(0.3,0.5)$ & $\alpha \times$ & $(0,1)$ & $\mathrm{U}(0.3$ & $.5)$ & $C_{r} \times \mathrm{U}(0,1)$ & $C_{t} \times \mathrm{U}(0,1)$ \\
\hline
\end{tabular}

\section{Structures' Analysis}

In this subsection, numerical examples are executed by all proposed models and the results are compared with each other.

Optimum solutions for all of the six structures are calculated for 1000 test problems, in order to explore the behavior of the proposed models. Three of these test problems are presented in Table 4, and Figure 1 represents their optimum solutions.

Table 4. Test Problems (T.P.)

$\begin{array}{lccccccccccccc}\text { Parameter } & \boldsymbol{c}_{\boldsymbol{m}} & \boldsymbol{c}_{\boldsymbol{r}} & \boldsymbol{c}_{\boldsymbol{t}} & \boldsymbol{a}_{\boldsymbol{n}} & \boldsymbol{a}_{\boldsymbol{r}} & \boldsymbol{\alpha}_{\boldsymbol{n}} & \boldsymbol{\alpha}_{\boldsymbol{r}} & \boldsymbol{\beta}_{\boldsymbol{n}} & \boldsymbol{\beta}_{\boldsymbol{r}} & \boldsymbol{b} & \boldsymbol{\lambda} & \boldsymbol{R P}_{\boldsymbol{1}} & \boldsymbol{R P}_{2} \\ \text { T.P. 1 } & 20 & 10 & 5 & 566 & 174 & 0.47 & 0.487 & 0.319 & 0.369 & 43 & 0.378 & 7 & 1 \\ & & & & & & & & & & & & & \\ \text { T.P. 2 } & 16 & 7 & 4 & 529 & 239 & 0.451 & 0.376 & 0.256 & 0.028 & 3 & 0.406 & 6 & 4 \\ \text { T.P. 3 } & 14 & 5 & 3 & 532 & 216 & 0.333 & 0.333 & 0.201 & 0.201 & 14 & 0.431 & 4 & 3\end{array}$




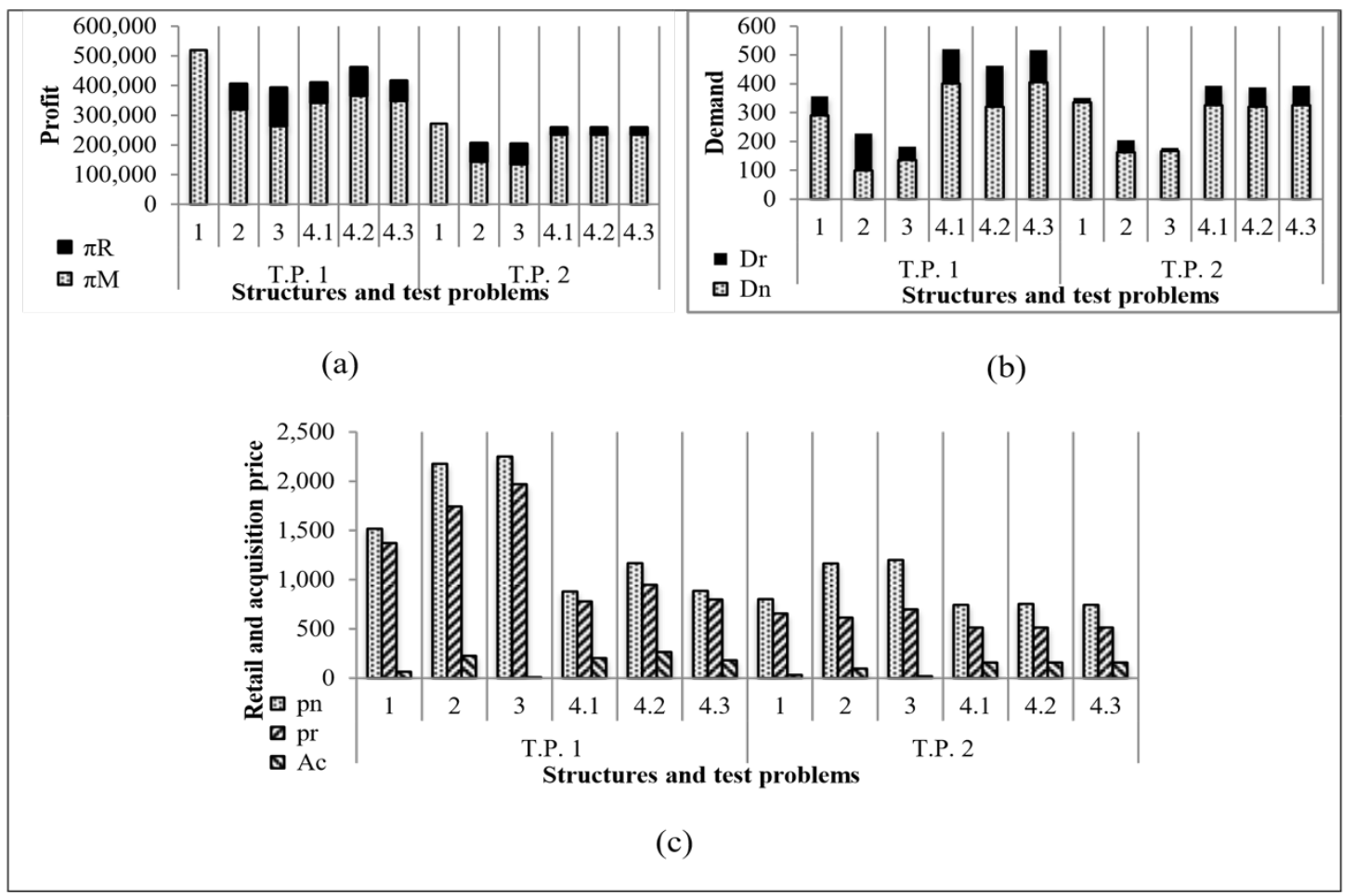

Figure 1. Optimal results of the two test problems: (a) profit; (b) demand; (c) price.

As it is indicated before, the first structure (centralized) provides the maximum profit of the whole supply chain, because the centralized decision-maker can always make the same decisions as to the collection of decentralized decision-makers. Clearly, if the manufacturer determines not to handle retailing activities, he will lose a part of his profit. Rationally, the retailer prefers to handle backward flow as well as forward one, to increase his profit.

Although outsourcing the acquisition activities decreases the manufacturer's profit, the difference is not significant in comparison with his total profit. Hence, the manufacturers should not oppose doing so.

The manufacturer should take control of both brand-new and remanufactured products, because the results show that, not only the fourth structure provides lower selling prices, but also the manufacturer's profit increases too. In other words, such a structure makes a new competition and both of the players need to decrease their selling prices, and customers can benefit from such competition, while the retailer's profit is shared between manufacturer and remanufacturer.

Besides, the leadership of the network affects profits. The Nash equilibrium (structure 4.1) makes both of the players to lose their profits. If the manufacturer is the leader of the Stackelberg game (structure 4.2), both of the manufacturer and remanufacturer will benefit in comparison with the leadership of the retailer (structure 4.3). Usually, the remanufacturer may not prefer to take the leadership of the supply chain. Because the remanufacturer needs to maximize the demand of remanufactured products $\left(D_{r}\right)$, by decreasing the price of remanufactured products $\left(p_{r}\right)$, while the manufacturer decreases the price of the brand-new products $\left(p_{n}\right)$, in order to compete with the remanufacturer. On the other hand, the remanufacturer needs to return the more used product (increasing $R$ ) in order 
to remanufacture them by increasing the acquisition price $\left(A_{c}\right)$, which results in less profit margin for the remanufacturer. This situation decreases the total profit of the whole supply chain and increases the demand for remanufactured and brand-new products, which is confirmed by the simulation study as well.

As mentioned previously, the prices of remanufactured and brand-new products in the fourth structure are relatively cheaper than the other structures, which results in greater demand for remanufactured and brand-new products and greater acquisition price for returning more used products to be remanufactured. Because, when the manufacturer and remanufacturer compete with each other, they will decrease their selling price in order to reach more market share. Besides, as the selling prices are low, the customers are more satisfied and more used products will be returned for the remanufacturing process. As a conclusion, the fourth structure satisfies more customers, without consuming more raw materials, while the total profit of the whole supply chain remains reasonable.

\section{Sensitivity Analysis}

This subsection aims to analyze the impacts of $\alpha, \beta, \lambda$, on the optimal solutions. The T.P. 3 , which is defined by Table 4 , is considered as the base model of all analyzes and one of its parameters is changed in order to clarify sensitivity to that parameter. Figure 2 represents the results. 

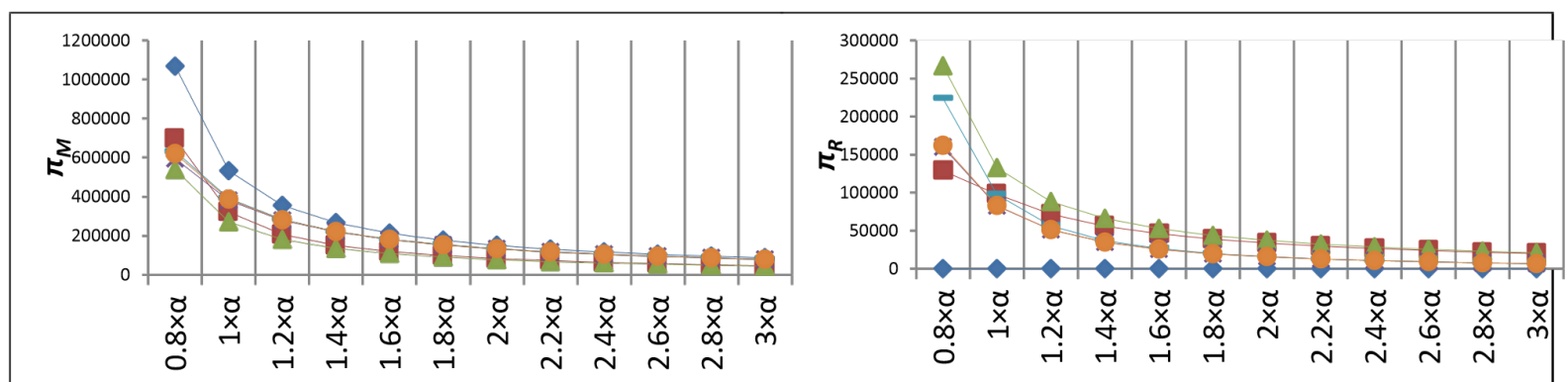

(a) Sensitivity to $\alpha$
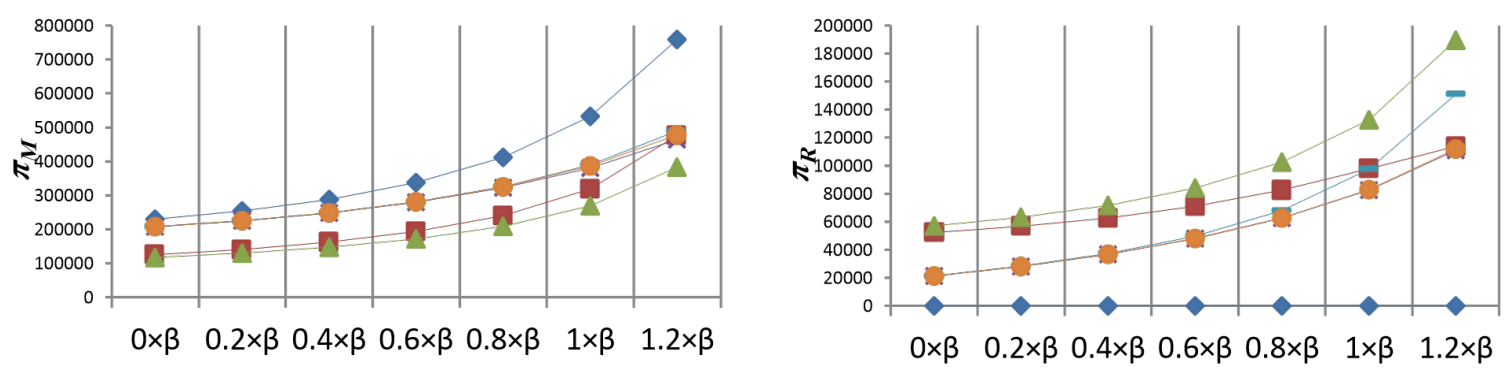

(b) Sensitivity to $\beta$
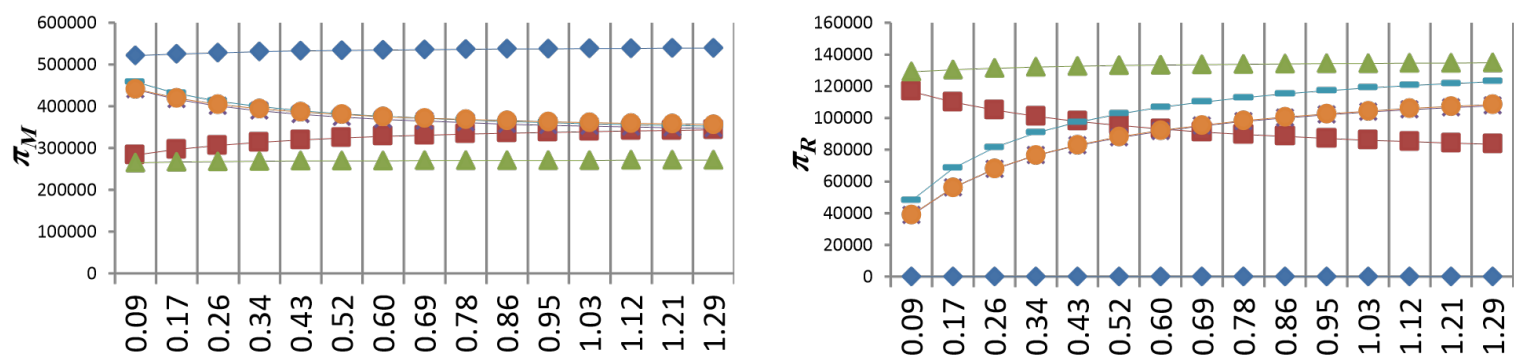

(c) Sensitivity to $\lambda$

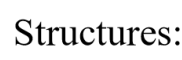

\subsection{4 .24 .3}

Figure 2. Sensitivity of optimal solution to $\alpha, \beta, \lambda$.

If the coefficients of self-price demand sensitivity of a product $(\alpha)$ increase, the optimal selling prices will decrease in order to avoid demand reduction, which leads to less profit. On the other hand, as the coefficients of demand sensitivity to alternative product $(\beta)$ increase, the optimal selling prices can be increased without losing the demand level, which leads to more profit. In addition, the behavior of the demand level of remanufactured products, and the acquisition price $\left(A_{c}\right)$ are always similar to each other (as it is proven by Theorem 1). Besides, as the coefficients of return sensitivity to acquisition price $(\lambda)$ increase enough, the remanufacturer can return much more 
consumed products by increasing acquisition price, which increases remanufacturer's profit margin and allows him to reduce the price of remanufactured products while profit margin of the manufacturer is not increased. Figure 2 confirms such an argument. As it is explained, the behaviors of the structures are completely different by increasing the coefficient of return sensitivity to the acquisition price. Besides, each of the structures can provide a larger profit (for the manufacturer, retailer, or remanufacturer) in different conditions.

\section{Managerial Insights}

As it is explained, the solutions and behavior of the structures vary in different situations. Each structure can provide maximum profit (for the whole supply chain, just one player, customers, or even environment) in some conditions. Decision-makers may choose situations such as (de)centralizing, competition, cooperation, separation/ integration of (re)manufacturing, and retailing activities. Also, the decision-makers may have some constraints to configure the situations. For example, in some high-tech industries, separations of manufacturing and remanufacturing activities are not possible/ economic. Although integrating (centralizing) CLSC activities increase the total supply chain profit, sometimes there are other strategies that make companies reduce their profit for other benefits such as customer satisfaction, social responsibility, governmental regulations, environmental protection, and etc.

This paper provides the decision-makers precious managerial insights in order to benefit considerably from various situations for remanufacturing and acquisition activities as well as manufacturing and distribution activities. As it is mentioned before, there is no proof to determine the best structure. The sensitivity analysis shows that the profit functions behave differently and each of them can be larger than the others (except the centralized profit function that is always the maximum one). Hence, we should compare the models statistically by simulation studies. We have simulated 1000 mathematical models. Parameters of the models are generated by random distributions as Table 3 shows. Expectation values and standard deviations of the results are briefly reported in Table 5 .

Table 5. Simulation results.

\begin{tabular}{|c|c|c|c|c|c|c|c|c|c|c|c|c|c|c|c|}
\hline \multirow{2}{*}{ Str. } & \multirow{2}{*}{$\begin{array}{l}\text { Total } \\
\text { profit }\end{array}$} & \multicolumn{7}{|c|}{ Expectation values } & \multicolumn{7}{|c|}{ Standard deviations } \\
\hline & & $\pi_{M}$ & $\pi_{R}$ & $D_{n}$ & $D_{r}$ & $p_{n}$ & $p_{r}$ & $A_{c}$ & $\pi_{M}$ & $\pi_{R}$ & $D_{n}$ & $D_{r}$ & $p_{n}$ & $p_{r}$ & $A_{c}$ \\
\hline 1 & 291704 & 291704 & $\mathrm{NaN}$ & 234 & 50 & 871 & 725 & 78 & 192197 & $\mathrm{NaN}$ & 117 & 27 & 543 & 488 & 48 \\
\hline 2 & 227917 & 169870 & 58047 & 104 & 70 & 1270 & 848 & 128 & 116825 & 34177 & 53 & 40 & 781 & 591 & 79 \\
\hline 3 & 220984 & 148492 & 72493 & 114 & 33 & 1299 & 961 & 37 & 97140 & 47899 & 57 & 17 & 812 & 687 & 32 \\
\hline 4.1 & 268497 & 227920 & 40577 & 264 & 78 & 698 & 555 & 148 & 134140 & 29209 & 135 & 43 & 376 & 312 & 86 \\
\hline 4.2 & 276679 & 231208 & 45471 & 244 & 82 & 768 & 584 & 158 & 138153 & 36236 & 122 & 47 & 435 & 342 & 96 \\
\hline 4.3 & 270168 & 229512 & 40657 & 265 & 76 & 700 & 562 & 142 & 136052 & 29335 & 136 & 41 & 378 & 319 & 82 \\
\hline
\end{tabular}

We provide managerial insights from the point of view of five players: 1- Manufacturer, 2- Remanufacturer, 3Retailer, 4- Customer, 5- Government i.e. environment/social protection. These insights are achieved by statistical hypothesis tests over the 1000 simulated test problems, which are designed to be able to fit practical environments. 


\section{Manufacturer Best Strategy}

The first structure provides maximum expected value of the manufacturer's profit, and the worst strategy of the manufacturer is to outsource both of the retailing and collection activities. Hypothesis tests show that even if the manufacturer discards remanufacturing (structure 4) he will gain more profit than the situations in which retailing and acquisition activities are outsourced. The retailer absorbs profit share and affects the market. Nowadays, several manufacturers such as Dell realized this fact and distribute their products by multichannel (online and retailing) simultaneously. Moreover, several researchers have investigated multi-channel distribution strategies (Wu and Ross 2018).

\section{Remanufacturer Best Strategy}

The fourth structure considers the remanufacturer in the supply chain network. The maximum expected value of the remanufacturer's profit occurs through the leadership of manufacturer (structure 4.2). As it is discussed before, if the remanufacturer leads the supply chain, profit of the manufacturer and remanufacturer will be decreased. Some of the remanufacturers prefer not to lead the market such as remanufacturing sites of Dell and GENCO, in order to increase their profit and the whole supply chain as well.

\section{Retailer Best Strategy}

The second and third structures consider the retailer in the supply chain network. The maximum expected value of the retailer's profit is provided by the third structure. It indicates that obviously, the retailer prefers to handle both of the retailing and acquisition activities, while the manufacturer's profit does not reduce significantly (in comparison with structure 2). In other words, if the manufacturer/remanufacturer decides to outsource the retailing activities, he can consider outsourcing the collecting activities as well. Several companies follow such strategy e.g. Xerox, Kodak, Samsung, and etc.

\section{Customer Best Situation}

The customers prefer low selling price and high acquisition price (quality level is not considered by the proposed model). The maximum expectation value of total demand $\left(D_{n}+D_{r}\right)$ is provided by the fourth structure. In other words, the customers will not prefer the situations in which the retailer handles retailing or collecting activities unless customers' preferences have been considered by the decision-makers. As it is mentioned previously, the retailer increases selling prices and decreases acquisition price in order to increase his profit margin. Hence, all of the players prefer the direct distribution and collection channels. It is suggested that the manufacturers do not outsource distribution and/or collection activities if the customer satisfaction level is their first priority. Several international companies such as Mercedes-Benz, LG, and etc. use the outsourcing strategies, but they have some regulations in order to appreciate their customers.

\section{Government Best Strategy}

Usually, governments pass legislation that restricts the utilization of raw materials and motivates firms to re-use and recycle the parts. Hence, the main goal of governments is to increase remanufacturing activities. Simulation studies show that maximum expectation value of the $D_{r}$ is achieved by structure 4.2. However, total profit of the whole supply chain will not decrease more than $10 \%$ (with $95 \%$ confidence level) if the manufacturer chooses structure 4.2 instead of the first structure. It is obvious that the worst cases in the government's sight are the second and third structures as well as manufacturer's sight. Hence, the governments may not prefer the retailers to carry out collection activities in CLSCs. Unless there is a good motivation for customers to return their products. If there is a 
lack of motivation (social or beneficial) for customers to return their used products, outsourcing collection activities will reduce the number of returned products. On the other hand, if there is enough motivation for returning the used products, the second and third structures provide minimum collection cost. This is the main reason which describes why most organizations prefer to collect consumed products through retailers. Although this is the cheapest way to collect used products from the market, the manufacturer's profit is minimized by non-regulated retailers, and the remanufacturing activities are minimized too.

Please note that these discussions are made by simulation studies and statistical hypothesis tests (with $95 \%$ confidence level), but there may be specific situations which lead to different results. Section 0 describes such a situation by over increasing the parameters for the sensitivity analysis.

\section{CONCLUSION}

This study investigates pricing and acquisition management problems in a CLSC network, in which the brandnew and remanufactured products are distinguished in the market. It explores various supply channel structures that cover various conditions in a practical environment.

The proposed structures are analyzed by simulation studies and sensitivity analyses. The solutions and behavior of the structures vary in different situations. Each structure may provide maximum profit (for the whole supply chain, just one player, customers, or even environment) in some conditions. This article clarifies that, in some cases, although integration of the activities increases the total profit, it cannot guarantee the preferences of other players.

Future researchers may consider some directions to expand the application of the proposed model. Such as considering the more competitive market in which there are several competitors who (re)manufacture products. Investigation of the impact of launching a new product on the structures is a very attractive topic. Considering the quality of returned products as well as the quantity is another issue which can be considered by future researchers. Furthermore, we have only engaged immediate decisions, which manifest the impacts on the market instantly. Extending the problems to long term equilibrium can expand the application of such models. Managers usually have concerns about non-price actions such as educational aids, guarantee, brand investments, and etc. that should be explored by future researchers.

\section{REFERENCES}

Atasu, Atalay, Miklos Sarvary, and Luk N Van Wassenhove. 2008. "Remanufacturing as a Marketing Strategy.” Management Science 54 (10): 1731-46.

Barron, Emmanual N. 2013. Game Theory: An Introduction. Vol. 2. John Wiley \& Sons.

Cai, Xiaoqiang, Minghui Lai, Xiang Li, Yongjian Li, and Xianyi Wu. 2014. "Optimal Acquisition and Production Policy in a Hybrid Manufacturing/Remanufacturing System with Core Acquisition at Different Quality Levels.” European Journal of Operational Research 233 (2): 374-82.

Cao, Jian, Xuemei Zhang, Liling Hu, Jiayang Xu, Yunwen Zhao, Gengui Zhou, and Jerald L Schnoor. 2018. "EPR Regulation and Reverse Supply Chain Strategy on Remanufacturing." Computers \& Industrial Engineering 125: 279-97. https://doi.org/https://doi.org/10.1016/j.cie.2018.08.034.

Chen, Jen-Ming, and C I Chang. 2012a. "The Economics of a Closed-Loop Supply Chain with Remanufacturing." Journal of the Operational Research Society 63 (10): 1323-35. 
Chen, Jen-Ming, and Chia-I Chang. 2012b. "The Co-Opetitive Strategy of a Closed-Loop Supply Chain with Remanufacturing." Transportation Research Part E: Logistics and Transportation Review 48 (2): 387-400. https://doi.org/https://doi.org/10.1016/j.tre.2011.10.001.

Dye, Chung-Yuan, and Chih-Te Yang. 2016. "Optimal Dynamic Pricing and Preservation Technology Investment for Deteriorating Products with Reference Price Effects." Omega 62: 52-67.

https://doi.org/https://doi.org/10.1016/j.omega.2015.08.009.

Gan, Shu-San, I Nyoman Pujawan, Suparno, and Basuki Widodo. 2017. "Pricing Decision for New and Remanufactured Product in a Closed-Loop Supply Chain with Separate Sales-Channel." International Journal of Production Economics 190:

$120-32$. https://doi.org/https://doi.org/10.1016/j.ijpe.2016.08.016.

Gan, W, L Peng, D Li, L Han, and C Zhang. 2019. “A Coordinated Revenue-Sharing-Based Pricing Decision Model for Remanufactured Products in Carbon Cap and Trade Regulated Closed-Loop Supply Chain." IEEE Access

7: 142879-93. https://doi.org/10.1109/ACCESS.2019.2943385.

Gao, Juhong, Hongshuai Han, Liting Hou, and Haiyan Wang. 2016. "Pricing and Effort Decisions in a ClosedLoop Supply Chain under Different Channel Power Structures." Journal of Cleaner Production 112: 204357.

Guide Jr, V Daniel R, and Jiayi Li. 2010. "The Potential for Cannibalization of New Products Sales by Remanufactured Products." Decision Sciences 41 (3): 547-72.

Guo, Shu, Bin Shen, Tsan-Ming Choi, and Sojin Jung. 2017. "A Review on Supply Chain Contracts in Reverse Logistics: Supply Chain Structures and Channel Leaderships.” Journal of Cleaner Production 144: 387-402. https://doi.org/https://doi.org/10.1016/j.jclepro.2016.12.112.

He, Yuanjie. 2015. "Acquisition Pricing and Remanufacturing Decisions in a Closed-Loop Supply Chain." International Journal of Production Economics 163 (September 2014): 48-60. https://doi.org/10.1016/j.ijpe.2015.02.002.

Hong, Z, and $\mathbf{H}$ Zhang. 2019. "Pricing and Acquisition for Remanufacturing with Interactive Production Constraints." Journal of Cleaner Production 216: 197-216.

Jena, Sarat Kumar, and S P Sarmah. 2016. "Future Aspect of Acquisition Management in Closed-Loop Supply Chain.” International Journal of Sustainable Engineering 9 (4): 266-76. https://doi.org/10.1080/19397038.2016.1181120.

Kainuma, Yasutaka. 2019. "Investigation on Pricing Decisions of Remanufactured Products and Profit of Supply Chain.” In ICORES, 253-57.

Li, Kai, Jing Liu, Hong Fu, and Bohai Liu. 2020. “Acquisition and Pricing Strategies in Hybrid ManufacturingRemanufacturing Systems." Journal of Manufacturing Systems 57: 217-30. https://doi.org/https://doi.org/10.1016/j.jmsy.2020.09.006.

Liu, Wenjie, Dingzhi Qin, Ningning Shen, Jing Zhang, Mingzhou Jin, Naiming Xie, Jian Chen, and Xiangyun Chang. 2020. "Optimal Pricing for a Multi-Echelon Closed Loop Supply Chain with Different Power Structures and Product Dual Differences.” Journal of Cleaner Production 257: 120281. https://doi.org/https://doi.org/10.1016/j.jclepro.2020.120281.

Liu, Zhuojun, Jing Chen, Claver Diallo, and Uday Venkatadri. 2020. "Pricing and Production

Decisions in a Dual-Channel Closed-Loop Supply Chain with (Re)Manufacturing." International Journal of Production Economics, 107935. https://doi.org/https://doi.org/10.1016/j.ijpe.2020.107935. 
Ma, Zu-Jun, Qin Zhou, Ying Dai, and Jiuh-Biing Sheu. 2017. "Optimal Pricing Decisions under the Coexistence of 'Trade Old for New' and 'Trade Old for Remanufactured' Programs." Transportation Research Part E: Logistics and Transportation Review 106: 337-52. https://doi.org/https://doi.org/10.1016/j.tre.2017.08.012.

Madani, Seyed Reza, and Morteza Rasti-Barzoki. 2017. "Sustainable Supply Chain Management with Pricing, Greening and Governmental Tariffs Determining Strategies: A Game-Theoretic Approach." Computers \& Industrial Engineering 105: 287-98. https://doi.org/https://doi.org/10.1016/j.cie.2017.01.017.

Mahmoudi, Reza, and Morteza Rasti-Barzoki. 2018. "Sustainable Supply Chains under Government Intervention with a Real-World Case Study: An Evolutionary Game Theoretic Approach." Computers \& Industrial Engineering 116: 130-43. https://doi.org/https://doi.org/10.1016/j.cie.2017.12.028.

Miao, Zhaowei, Ke Fu, Zhiqiang Xia, and Yu Wang. 2017. "Models for Closed-Loop Supply Chain with TradeIns." Omega 66: 308-26. https://doi.org/https://doi.org/10.1016/j.omega.2015.11.001.

Mitra, Subrata. 2016. "Models to Explore Remanufacturing as a Competitive Strategy under Duopoly." Omega 59: 215-27. https://doi.org/https://doi.org/10.1016/j.omega.2015.06.009.

Ovchinnikov, Anton. 2011. "Revenue and Cost Management for Remanufactured Products." Production and Operations Management 20 (6): 824-40.

Ramani, Vinay, and Pietro De Giovanni. 2017. "A Two-Period Model of Product Cannibalization in an Atypical Closed-Loop Supply Chain with Endogenous Returns: The Case of DellReconnect." European Journal of Operational Research 262 (3): 1009- 27.

Rezapour, Shabnam, Reza Zanjirani Farahani, Behnam Fahimnia, Kannan Govindan, and Yalda Mansouri. 2015. "Competitive Closed-Loop Supply Chain Network Design with Price-Dependent Demands." Journal of Cleaner Production 93: 251-72.

Taheri-Moghadam, Alireza, Jafar Razmi, Fariborz Jolai, and Ata Allah Taleizadeh. 2019. "Integrated Competitive Pricing and Transshipment Problem for Short Life Cycle Products' Supply Chain.” International Journal of Engineering 32 (8): 1192-99. https://doi.org/10.5829/ije.2019.32.08b.16.

Taleizadeh, Ata Allah, Farnoosh Haghighi, and Seyed Taghi Akhavan Niaki. 2019. "Modeling and Solving a Sustainable Closed Loop Supply Chain Problem with Pricing Decisions and Discounts on Returned Products." Journal of Cleaner Production 207: 163-81.

https://doi.org/https://doi.org/10.1016/j.jclepro.2018.09.198.

Urruty, Hiriart, Jean Baptiste, Strodiot, Jean Jacques, Nguyen, and V Hien. 1984. "Generalized Hessian Matrix and Second-Order Optimality Conditions for Problems WithC 1, 1 Data." Applied Mathematics \& Optimization 11 (1): 43-56. Vorasayan, Jumpol, and Sarah M Ryan. 2006. "Optimal Price and Quantity of Refurbished Products." Production and Operations Management 15 (3): 369-83.

Wang, Limin, Qiankun Song, and Zhenjiang Zhao. 2020. "The Optimal Pricing of DualChannel Supply Chain with the Third Party Product Recovery and Sales Effort.” Edited by Xiaodi Li. Complexity 2020: 4951341. https://doi.org/10.1155/2020/4951341.

Wu, Desheng Dash, and Anthony Ross. 2018. "Pricing Optimization, Channel and Uncertainty." International Journal of Production Research 56 (5): 1733-37. https://doi.org/10.1080/00207543.2017.1398433.

Zhao, Jing, Weiyu Liu, and Jie Wei. 2013. "Competition under Manufacturer Service and Price in Fuzzy Environments." Knowledge-Based Systems 50 (September): 121-33. https://doi.org/10.1016/j.knosys.2013.06.003.

Zhou, Liangchuan, Surendra M Gupta, Yuki Kinoshita, and Tetsuo Yamada. 2017. "Pricing Decision Models for Remanufactured Short-Life Cycle Technology Products with Generation Consideration." Procedia CIRP 61: 195-200. https://doi.org/https://doi.org/10.1016/j.procir.2016.11.208. 
Zhou, Yancong, Xudong Guo, and Xiaochen Sun. 2016. “Acquisition Pricing and Inventory

Decisions on Dual-Source Spare-Part System with Final Production and Remanufacturing." Scientific Programming 2016.

\section{APPENDIX A: PROOF OF Theorem 1,}

We want to prove that the optimal decision variables $\left(p_{n}{ }^{*}, p_{r}{ }^{*}, A_{c}{ }^{*}\right)$ are characterized by $D_{r}\left(p_{n}{ }^{*}, p_{r}{ }^{*}\right)=R\left(A_{c}{ }^{*}\right)$. This equation indicates that the demand for remanufactured products is equal to the amount of returned products in an optimal solution.

There are three different conditions for every solution: $1-D_{r}>R, 2-D_{r}<R, 3-D_{r}=R$.

The condition of $D_{r}>R$ means that $\min \left(D_{r}, R\right)=R$. By using equations (2) to (4) we have:

$$
\begin{aligned}
& \pi^{I}\left(p_{n}, p_{r}, A_{c}\right)=D_{n}\left(p_{n}, p_{r}\right) \times\left(p_{n}-c_{m}-c_{t}\right)+R\left(A_{c}\right) \times\left(p_{r}-A_{c}-c_{r}-c_{t}\right) \\
& \Rightarrow \exists \varepsilon>0 ; \\
& \pi^{I}\left(p_{n}, p_{r}+\varepsilon, A_{c}\right)=D_{n}\left(p_{n}, p_{r}+\varepsilon\right) \times\left(p_{n}-c_{m}-c_{t}\right)+R\left(A_{c}\right) \times\left(\left(p_{r}+\varepsilon\right)-A_{c}-c_{r}-c_{t}\right) \\
& \Rightarrow \pi^{I}\left(p_{n}, p_{r}+\varepsilon, A_{c}\right)=\pi^{I}\left(p_{n}, p_{r}, A_{c}\right)+\varepsilon\left(\beta\left(p_{n}-c_{m}-c_{t}\right)+\left(b+\lambda A_{c}\right)\right) \\
& \Rightarrow \pi^{I}\left(p_{n}, p_{r}+\varepsilon, A_{c}\right)>\pi^{I}\left(p_{n}, p_{r}, A_{c}\right)
\end{aligned}
$$

According to the basic assumptions, $p_{n}-c_{m}-c_{t}>0$ and $b+\lambda A_{c}>0$. Hence, we have $f(\varepsilon)>0$ which indicates that $\pi^{I}\left(p_{n}, p_{r}, A_{c}\right)<\pi^{I}\left(p_{n}, p_{r}+\varepsilon, A_{c}\right)$, and $\pi^{I}\left(p_{n}, p_{r}, A_{c}\right)$ cannot be an optimal solution. In other words, the optimal solution will never fit the first condition $\left(D_{r}>R\right.$ is not true for the optimal solution).

The condition of $D_{r}<R$ means that $\min \left(D_{r}, R\right)=D_{r}$. By using equations (2) to (4) we have:

$$
\begin{aligned}
& \pi^{I}\left(p_{n}, p_{r}, A_{c}\right)=D_{n}\left(p_{n}, p_{r}\right) \times\left(p_{n}-c_{m}-c_{t}\right)+D_{r}\left(p_{n}, p_{r}\right) \times\left(p_{r}-A_{c}-c_{r}-c_{t}\right) \\
& \Rightarrow \exists \varepsilon>0 ; \\
& \pi^{I}\left(p_{n}, p_{r}, A_{c}-\varepsilon\right)=D_{n}\left(p_{n}, p_{r}\right) \times\left(p_{n}-c_{m}-c_{t}\right)+D_{r}\left(p_{n}, p_{r}\right) \times\left(p_{r}-\left(A_{c}-\varepsilon\right)-c_{r}-c_{t}\right) \\
& \Rightarrow \pi^{I}\left(p_{n}, p_{r}, A_{c}-\varepsilon\right)=\pi^{I}\left(p_{n}, p_{r}, A_{c}\right)+\varepsilon D_{r}\left(p_{n}, p_{r}\right) \\
& \Rightarrow \pi^{I}\left(p_{n}, p_{r}, A_{c}-\varepsilon\right)>\pi^{I}\left(p_{n}, p_{r}, A_{c}\right)
\end{aligned}
$$

According to the basic assumptions, $D_{r}>0$, we have $\pi^{I}\left(p_{n}, p_{r}, A_{c}\right)<\pi^{I}\left(p_{n}, p_{r}, A_{c}+\varepsilon\right)$. This confirms that $\pi^{I}\left(p_{n}, p_{r}\right.$, $A_{c}$ ) cannot be an optimal solution. In other words, the optimal solution will never fit the second condition $\left(D_{r}<R\right.$ is not true for the optimal solution).

According to equations (A. 1) and (A. 2), we have $D_{r}{ }^{*}=R^{*}$ for the optimal solution. This indicates that, for the optimal solution, the minimum of $R$ and $D_{r}$ can be calculated by equation (A. 3 ). 
For optimal solution: $R\left(A_{c}^{*}\right)=D_{r}\left(p_{n}^{*}, p_{r}{ }^{*}\right) \Rightarrow b+\lambda A_{c}^{*}=a_{r}-\alpha \times p_{r}{ }^{*}+\beta \times p_{n}{ }^{*}$

$$
\Rightarrow \min \left(R\left(A_{c}^{*}\right), D_{r}\left(p_{n}^{*}, p_{r}^{*}\right)\right)=b+\lambda A_{c}^{*}=a_{r}-\alpha \times p_{r}{ }^{*}+\beta \times p_{n}{ }^{*}
$$

By using equation (A. 3), we can always relax one of the variables $A_{c}{ }^{*}, p_{n}{ }^{*}, p_{r}{ }^{*}$ (only for the optimal solution).

\section{APPENDIX B: CONCAVITY OF PROFIT FUNCTIONS,}

Concavity of the profit functions is checked by the Hessian matrix. If the Hessian matrix of a function is negative definite, the function is jointly concave in its own variables (Urruty et al. 1984).

\section{The First Structure}

The hessian matrix of $\pi^{I}\left(p_{n}{ }^{*}, p_{r}{ }^{*}\right)$ is calculated by equation (B. 1), as the Hessian matrix is negative definite, $\pi^{I}\left(p_{n}{ }^{*}, p_{r}{ }^{*}\right)$ is a jointly concave function in $p_{n}{ }^{*}, p_{r}{ }^{*}$. Please note that, according to the basic assumptions, all of the parameters are assumed as positive numbers, and $\alpha>\beta$.

$$
\begin{aligned}
& H\left(\pi^{I}\left(p_{n}{ }^{*}, p_{r}{ }^{*}\right)\right)=\left[\begin{array}{cc}
\frac{\partial^{2} \pi^{I}}{\partial p^{2}{ }^{*}} & \frac{\partial^{2} \pi^{I}}{\partial p_{n}{ }^{*} \partial p_{r}{ }^{*}} \\
\frac{\partial^{2} \pi^{I}}{\partial p_{r}{ }^{*} \partial p_{n}{ }^{*}} & \frac{\partial^{2} \pi^{I}}{\partial p^{2}{ }_{r}}
\end{array}\right]=\left[\begin{array}{cr}
-2\left(\alpha+\frac{\beta^{2}}{\lambda}\right) & 2 \beta\left(1+\frac{\alpha}{\lambda}\right) \\
2 \beta\left(1+\frac{\alpha}{\lambda}\right) & -2\left(\alpha+\frac{\alpha^{2}}{\lambda}\right)
\end{array}\right] \\
& \stackrel{\substack{\alpha, \beta, \lambda \geq 0 \\
\alpha \beta \lambda}}{\Rightarrow}\left\{\begin{array}{l}
H\left(\pi^{I}\left(p_{n}{ }^{*}, p_{r}{ }^{*}\right)\right) \equiv\left[\begin{array}{ll}
- & + \\
+ & -
\end{array}\right] \\
H_{1}=-2\left(\alpha+\frac{\beta^{2}}{\lambda}\right)<0 \\
H_{2}=4\left(1+\frac{\alpha}{\lambda}\right)\left(\alpha^{2}-\beta^{2}\right)>0
\end{array} \Rightarrow H\right. \text { is negative definite }
\end{aligned}
$$

\section{The Second Structure}

The hessian matrix of $\pi_{M}^{I I}$ is calculated by equation (B. 2), as the Hessian matrix is negative semi-definite, $\pi_{M}{ }^{I I}$ is a concave function in $w_{n}{ }^{*}, w_{r}{ }^{*}$, and $A_{c}{ }^{*}$. The hessian matrix of $\pi_{R}{ }^{I I}$ is calculated by equation (B. 3), as the Hessian matrix is negative semi-definite, $\pi_{M}{ }^{I I}$ is a concave function in $p_{n}{ }^{*}$, and $p_{r}{ }^{*}$.

Please note that, according to the basic assumptions, all of the parameters are assumed as positive numbers, and $\alpha>\beta$. 


$$
\begin{aligned}
& H\left(\pi_{M}^{I I}\left(w_{n}{ }^{*}, w_{r}{ }^{*}, A_{c}{ }^{*}\right)\right)=\left[\begin{array}{ccc}
\frac{\partial^{2} \pi^{I I}}{\partial w_{n}{ }^{*}} & \frac{\partial^{2} \pi^{I I}}{\partial w_{n}{ }^{*} \partial w_{r}{ }^{*}} & \frac{\partial^{2} \pi^{I I}}{\partial w_{n}{ }^{*} \partial A_{c}{ }^{*}} \\
\frac{\partial^{2} \pi^{I I}}{\partial w_{r}{ }^{*} \partial w_{n}{ }^{*}} & \frac{\partial^{2} \pi^{I I}}{\partial w_{r}{ }^{* 2}} & \frac{\partial^{2} \pi^{I I}}{\partial w_{r}{ }^{*} \partial A_{c}{ }^{*}} \\
\frac{\partial^{2} \pi^{I I}}{\partial A_{c}{ }^{*} \partial w_{n}{ }^{*}} & \frac{\partial^{2} \pi^{I I}}{\partial A_{c}{ }^{*} \partial w_{r}{ }^{*}} & \frac{\partial^{2} \pi^{I I}}{\partial A_{c}^{* 2}}
\end{array}\right]=\left[\begin{array}{ccc}
\beta^{2}-\alpha^{2} & 0 & \frac{-\beta \lambda}{\alpha} \\
0 & 0 & \lambda \\
\frac{-\beta \lambda}{\alpha} & \lambda & -2 \lambda
\end{array}\right] \\
& \stackrel{\substack{\alpha, \beta, \lambda \geq 0 \\
\alpha>\beta}}{\Rightarrow}\left\{\begin{array}{l}
H \equiv\left[\begin{array}{lll}
- & 0 & - \\
0 & 0 & + \\
- & + & -
\end{array}\right] \\
H_{1}=\beta^{2}-\alpha^{2}<0 \\
H_{2}=0 \\
H_{3}=-\lambda^{2}\left(\beta^{2}-\alpha^{2}\right)<0
\end{array} \Rightarrow H\right. \text { is negative semi definite } \\
& H\left(\pi_{R}^{I I}\left(p_{n}{ }^{*}, p_{r}{ }^{*}\right)\right)=\left[\begin{array}{cc}
\frac{\partial^{2} \pi^{I I}}{\partial p^{2}{ }_{n}^{*}} & \frac{\partial^{2} \pi^{I I}}{\partial p_{n}{ }^{*} \partial p_{r}{ }^{*}} \\
\frac{\partial^{2} \pi^{I I}}{\partial p_{r}{ }^{*} \partial p_{n}{ }^{*}} & \frac{\partial^{2} \pi^{I I}}{\partial p^{2}{ }_{r}{ }^{*}}
\end{array}\right]=\left[\begin{array}{cc}
-2 \alpha & 2 \beta \\
2 \beta & -2 \alpha
\end{array}\right] \\
& \stackrel{\substack{\alpha, \beta, \lambda \geq 0 \\
\alpha>\beta}}{\Rightarrow}\left\{\begin{array}{l}
H \equiv\left[\begin{array}{l}
- \\
+
\end{array}\right] \\
H_{1}=-2 \alpha<0 \\
H_{2}=4\left(\alpha^{2}-\beta^{2}\right)>0
\end{array} \Rightarrow H\right. \text { is negative semi definite }
\end{aligned}
$$

\section{The Third Structure}

Concavity of $\pi_{M}^{I I I}$ and $\pi_{R}^{I I I}$ can be proven mathematically similar to the previous models. As the formulations are similar, the mathematical proof is not provided and only schematic form of profit functions are presented by Figure B. 1 and Figure B. 2. 

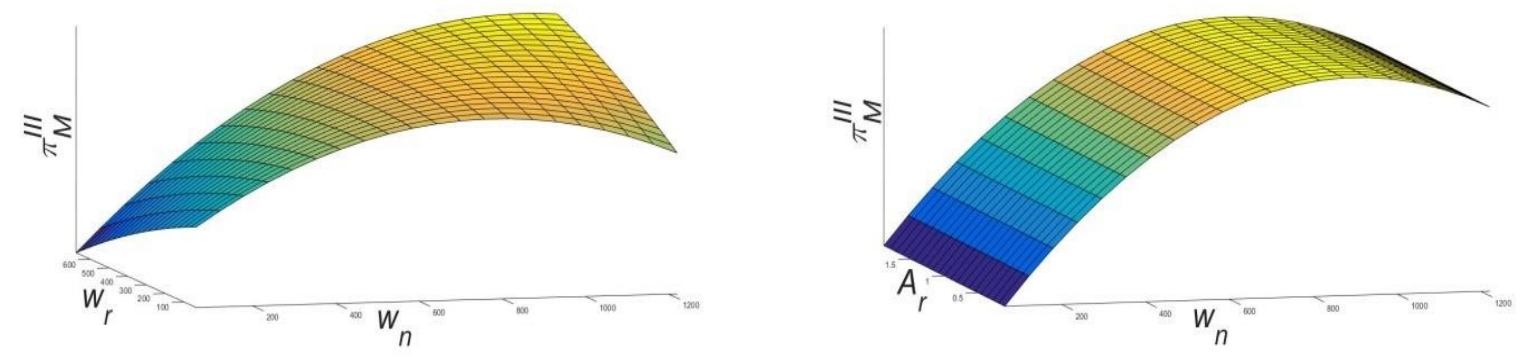

Figure B. 1. Schematic form of $\pi_{M}$ III .
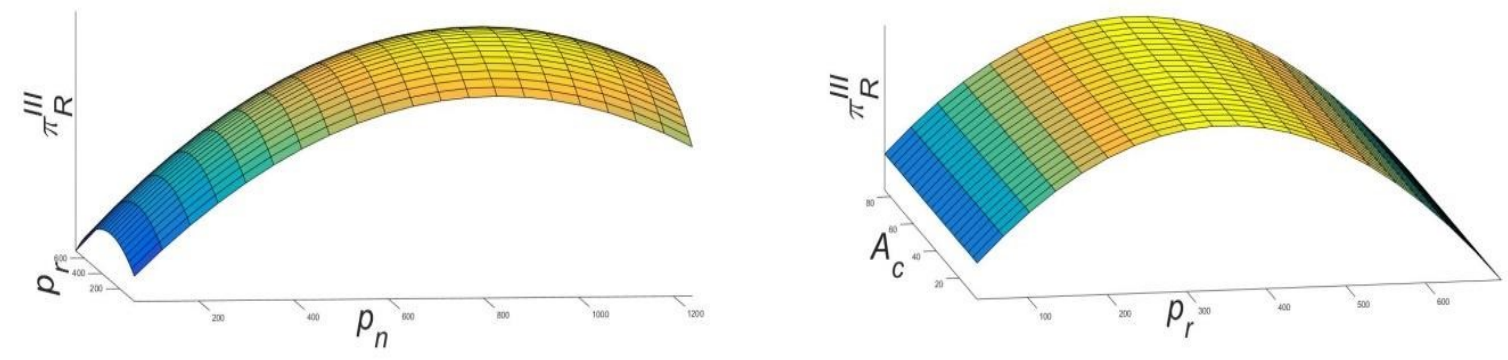

Figure B. 2. Schematic form of $\pi R$.

\section{The Fourth Structure}

Concavity of $\pi_{M}{ }^{I V}$ and $\pi_{R}^{I V}$ can be proven mathematically similar to the previous models. As the formulations are similar, the mathematical proof is not provided, and only schematic form of profit functions are presented by Figure B. 3.

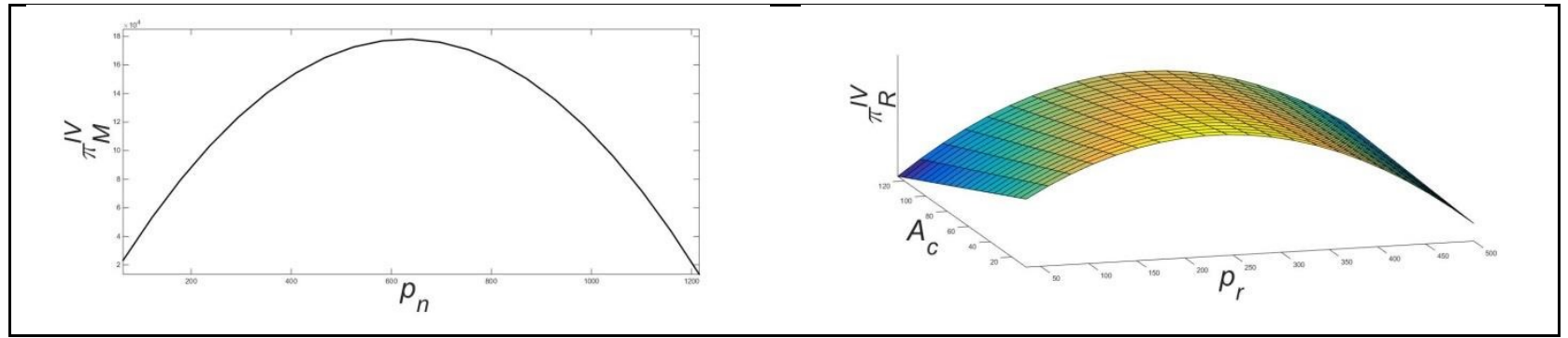

Figure B. 3. Schematic form of $\pi_{M}{ }^{I V}$, and $\pi_{R}{ }^{I V}$.

\section{APPENDIX C: CALCULATION OF THE OPTIMUM SOLUTIONS.}

The first-order derivatives of the profit functions and equalities of the optimal conditions are presented in order to achieve the optimal values of the variables. 


\section{The First Structure}

The partial first-order derivatives of $\pi^{I}\left(p_{n}{ }^{*}, p_{r}{ }^{*}\right)$ are presented by equations (C. 1) and (C. 2), and by solving equalities of equation (C. 3), the optimal variables are calculated.

$$
\begin{aligned}
& \frac{\partial \pi^{I}\left(p_{n}{ }^{*}, p_{r}{ }^{*}\right)}{\partial p_{n}{ }^{*}}=0 \Rightarrow\left(-\alpha-c_{m}-c_{t}\right)+\left(a_{n}+\beta p_{r}{ }^{*}\right)-2 \alpha p_{n}{ }^{*} \\
& +\beta\left(p_{r}^{*}-c_{r}-c_{t}-\frac{a_{r}-\alpha \times p_{r}^{*}-b}{\lambda}\right)-\frac{\beta}{\lambda}\left(a_{r}-\alpha \times p_{r}^{*}\right)-\frac{2 \beta^{2}}{\lambda} p_{n}^{*}=0 \\
& \Rightarrow-2\left(\alpha+\frac{\beta^{2}}{\lambda}\right) p_{n}{ }^{*}+2 \beta\left(1+\frac{\alpha}{\lambda}\right) p_{r}{ }^{*}+\left(-\alpha-c_{m}-c_{t}+a_{n}+\beta\left(-c_{r}-c_{t}-\frac{2 a_{r}-b}{\lambda}\right)\right)=0 \\
& K_{1} \quad K_{2} \quad K_{3} \\
& \frac{\partial \pi^{I}\left(p_{n}{ }^{*}, p_{r}{ }^{*}\right)}{\partial p_{r}{ }^{*}}=0 \Rightarrow \beta\left(p_{n}{ }^{*}-c_{m}-c_{t}\right)+\alpha\left(c_{r}+c_{t}+\frac{a_{r}+\beta \times p_{n}{ }^{*}-b}{\lambda}\right) \\
& +\left(a_{r}+\beta \times p_{n}^{*}\right)-2 \alpha p_{r}^{*}-\frac{2 \alpha^{2}}{\lambda} p_{r}^{*}=0 \\
& \Rightarrow 2\left(1+\frac{\alpha}{\lambda}\right) \beta p_{n}^{*}-2\left(1+\frac{\alpha}{\lambda}\right) \alpha p_{r}^{*}+\left(\beta\left(-c_{m}-c_{t}\right)+\alpha\left(c_{r}+c_{t}+\frac{a_{r}-b}{\lambda}\right)+a_{r}\right)=0 \\
& K_{2} \quad K_{4} \\
& \left\{\begin{array} { l } 
{ K _ { 1 } p _ { n } { } ^ { * } + K _ { 2 } p _ { r } ^ { * } + K _ { 3 } = 0 } \\
{ K _ { 2 } p _ { n } { } ^ { * } + K _ { 4 } p _ { r } { } ^ { * } + K _ { 5 } = 0 }
\end{array} \Rightarrow \left\{\begin{array}{l}
p_{n}{ }^{*}=\left(K_{4} K_{3}-\frac{K_{1} K_{4} K_{5}}{K_{2}}\right)\left(\frac{1}{K_{2}{ }^{2}-K_{1} K_{4}}\right)-\frac{K_{5}}{K_{2}} \\
p_{r}{ }^{*}=\left(\frac{K_{1} K_{5}}{K_{2}}-K_{3}\right)\left(\frac{K_{2}}{K_{2}{ }^{2}-K_{1} K_{4}}\right)
\end{array}\right.\right.
\end{aligned}
$$

\section{The Second Structure}

Equations (C. 4) and (C. 5) determine the best response of the retailer $\left(p_{n}{ }^{*}\right)$, by calculating the first-order derivative of $\pi_{R}^{I I}$ (from equation (12)). Equations (C. 6) to (C. 8) determine optimal values of the manufacturer's decision variables by calculating the first-order derivatives of $\pi R I I$.

$K_{i}$ is defined just for simplifying the equations and its formulations are presented by equations (C. 9) to (C. 17).

$$
\begin{aligned}
& \frac{\partial \pi_{R}{ }^{I I}\left(p_{n}{ }^{*}\right)}{\partial p_{n}{ }^{*}}=0 \Rightarrow p_{n}{ }^{*}\left(w_{n}{ }^{*}\right)=\frac{\left(w_{n}{ }^{*}+c_{t}\right)}{2}+\frac{\alpha a_{n}+\beta a_{r}}{2\left(\alpha^{2}-\beta^{2}\right)} \\
& p_{r}^{*}=\frac{\beta p_{n}^{*}-\lambda A_{c}^{*}+a_{r}-b}{\alpha} \Rightarrow p_{r}^{*}\left(w_{n}^{*}, A_{c}^{*}\right)=\frac{\beta\left(w_{n}{ }^{*}+c_{t}\right)}{2 \alpha}+\frac{\beta\left(\alpha a_{n}+\beta a_{r}\right)}{2 \alpha\left(\alpha^{2}-\beta^{2}\right)}+\frac{a_{r}-\lambda A_{c}^{*}-b}{\alpha} \\
& \frac{\partial \pi_{M}{ }^{I I}\left(w_{n}{ }^{*}, w_{r}{ }^{*}, A_{c}^{*}\right)}{\partial A_{c}^{*}}=0 \Rightarrow A_{c}{ }^{*}\left(w_{r}{ }^{*}, w_{n}^{*}\right)=\frac{w_{r}{ }^{*}-c_{r}-\frac{\beta}{\alpha}\left(w_{n}{ }^{*}-c_{m}\right)-\frac{b}{\lambda}}{2}
\end{aligned}
$$




$$
\begin{gathered}
\frac{\partial \pi_{M}{ }^{I I}\left(w_{n}{ }^{*}, w_{r}^{*}, A_{c}^{*}\right)}{\partial w_{n}{ }^{*}}=0 \Rightarrow w_{n}{ }^{*}\left(A_{c}^{*}\right)=\frac{c_{m}-c_{t}}{2}+\frac{\frac{\beta}{\alpha}\left(a_{r}-\lambda A_{c}^{*}-b\right)+a_{n}-\frac{\alpha a_{n}+\beta a_{r}}{2 \alpha}}{\alpha^{2}-\beta^{2}} \\
p_{r}{ }^{*}-w_{r}{ }^{*}-c_{t} \geq R P_{1} \Rightarrow \frac{\beta\left(w_{n}{ }^{*}+c_{t}\right)}{2 \alpha}+\frac{\beta\left(\alpha a_{n}+\beta a_{r}\right)}{2 \alpha\left(\alpha^{2}-\beta^{2}\right)}+\frac{a_{r}-\lambda A_{c}^{*}-b}{\alpha}-w_{r}{ }^{*}-c_{t} \geq R P_{1} \\
\Rightarrow_{r}{ }^{*} \leq \frac{\beta\left(w_{n}{ }^{*}+c_{t}\right)}{2 \alpha}+\frac{\beta\left(\alpha a_{n}+\beta a_{r}\right)}{2 \alpha\left(\alpha^{2}-\beta^{2}\right)}+\frac{a_{r}-\lambda A_{c}{ }^{*}-b}{\alpha}-c_{t}-R P_{1} \\
\Rightarrow_{r}{ }^{*}\left(w_{n}{ }^{*}, A_{c}{ }^{*}\right)=\frac{\beta\left(w_{n}{ }^{*}+c_{t}\right)}{2 \alpha}+\frac{\beta\left(\alpha a_{n}+\beta a_{r}\right)}{2 \alpha\left(\alpha^{2}-\beta^{2}\right)}+\frac{a_{r}-\lambda A_{c}^{*}-b}{\alpha}-c_{t}-R P_{1} \\
K_{6}=\frac{\beta\left(R P_{1}+c_{t}\right)-b+\frac{\lambda}{2}\left(c_{r}+\frac{b}{\lambda}-\frac{\beta c_{m}}{\alpha}\right)-\alpha\left(R P_{1}+c_{t}\right)}{\alpha+\beta}
\end{gathered}
$$

$K_{7}=\frac{\frac{\beta c_{m}}{\alpha}+K_{6}-c_{r}-\frac{b}{\lambda}}{2}$

$K_{8}=a_{n}+\left(\frac{\beta^{2}}{\alpha}-\alpha\right)\left(R P_{1}+c_{t}\right)+\frac{\beta\left(a_{r}-b\right)}{\alpha}$

$K_{9}=\frac{2 \beta^{2}}{2 \beta^{2}+\alpha \lambda}\left(\frac{b-a_{r}+\alpha\left(R P_{1}+c_{t}\right)}{\beta}-c_{t}-R P_{1}+\frac{\lambda}{2 \beta}\left(\frac{\alpha c_{m}}{\beta}-c_{r}-\frac{b}{\lambda}\right)\right)$

$K_{10}=\frac{\frac{\alpha c_{m}}{\beta}-c_{r}-\frac{b}{\lambda}-\frac{\alpha K_{9}}{\beta}}{2}$

$K_{11}=a_{n}+\frac{\alpha}{\beta}\left(a_{r}-b-\lambda K_{10}\right)+\left(\beta-\frac{\alpha^{2}}{\beta}\right)\left(R P_{1}+c_{t}\right)$

$K_{12}=a_{n}+(\beta-\alpha)\left(R P_{1}+c_{t}\right)$

$K_{13}=a_{r}+(\beta-\alpha)\left(R P_{1}+c_{t}\right)$

$K_{14}=-c_{r}-\frac{a_{r}+(\beta-\alpha)\left(R P_{1}+c_{t}\right)-b}{\lambda}$ 


\section{The Third Structure}

Equations (C. 18) and (C. 19), determine the best response of the retailer. By knowing the best response, the demand functions will be changes as equations (C. 20) and (C. 21) and the manufacturer's profit function $\left(\pi_{M}{ }^{I I I}\right)$ will be changed as equation (C. 22).

$$
\begin{aligned}
& \left.\begin{array}{l}
\frac{\partial \pi_{R}{ }^{I I I}}{\partial p_{n}{ }^{*}}=0 \\
\frac{\partial \pi_{R}{ }^{I I I}}{\partial p_{r}{ }^{*}}=0
\end{array}\right\} \Rightarrow p_{n}^{*}\left(w_{n}^{*}\right)=\frac{\left(\alpha^{2}-\beta\right)\left(w_{n}{ }^{*}+c_{t}\right)+\alpha a_{n}+\beta a_{r}}{2 \alpha^{2}-\beta(1+\beta)} \\
& \left.\begin{array}{l}
\frac{\partial \pi_{R}{ }^{I I I}}{\partial p_{n}{ }^{*}}=0 \\
\frac{\partial \pi_{R}{ }^{I I I}}{\partial p_{r}{ }^{*}}=0
\end{array}\right\} \Rightarrow p_{r}{ }^{*}\left(w_{n}{ }^{*}, w_{r}{ }^{*}, A_{r}{ }^{*}\right)=\frac{A_{r}{ }^{*}+w_{r}{ }^{*}+c_{t}}{2}+\frac{(\beta-1)\left(w_{n}{ }^{*}+c_{t}\right)+2 \alpha a_{r}+(1+\beta) a_{n}}{4 \alpha^{2}-2 \beta(1+\beta)} \\
& D_{n}=a_{n}-\alpha \times\left(\frac{\left(\alpha^{2}-\beta\right)\left(w_{n}{ }^{*}+c_{t}\right)+\alpha a_{n}+\beta a_{r}}{2 \alpha^{2}-\beta(1+\beta)}\right) \\
& +\beta \times\left(\frac{A_{r}{ }^{*}+w_{r}{ }^{*}+c_{t}}{2}+\frac{(\beta-1)\left(w_{n}{ }^{*}+c_{t}\right)+2 \alpha a_{r}+(1+\beta) a_{n}}{4 \alpha^{2}-2 \beta(1+\beta)}\right) \Rightarrow \\
& D_{n}=\left(\frac{2 \alpha\left(\beta-\alpha^{2}\right)+\beta(\beta-1)}{4 \alpha^{2}-2 \beta(1+\beta)}\right) w_{n}{ }^{*}+\left(\frac{\beta}{2}\right) w_{r}{ }^{*}+\left(\frac{\beta}{2}\right) A_{r}{ }^{*} \\
& K_{15} \\
& +\left(a_{n}+\frac{\beta c_{t}}{2}+\frac{\left(\beta(\beta-1)-2 \alpha\left(\alpha^{2}-\beta\right)\right) c_{t}+\left(\beta(1+\beta)-2 \alpha^{2}\right) a_{n}}{4 \alpha^{2}-2 \beta(1+\beta)}\right) \\
& K_{16} \\
& D_{r}=a_{r}-\alpha \times\left(\frac{A_{r}^{*}+w_{r}{ }^{*}+c_{t}}{2}+\frac{(\beta-1)\left(w_{n}{ }^{*}+c_{t}\right)+2 \alpha a_{r}+(1+\beta) a_{n}}{4 \alpha^{2}-2 \beta(1+\beta)}\right) \\
& +\beta \times\left(\frac{\left(\alpha^{2}-\beta\right)\left(w_{n}^{*}+c_{t}\right)+\alpha a_{n}+\beta a_{r}}{2 \alpha^{2}-\beta(1+\beta)}\right) \Rightarrow \\
& D_{r}=\left(\frac{\alpha(1-\beta)+2 \beta\left(\alpha^{2}-\beta\right)}{4 \alpha^{2}-2 \beta(1+\beta)}\right) w_{n}^{*}+\left(\frac{-\alpha}{2}\right) w_{r}^{*}+\left(\frac{-\alpha}{2}\right) A_{r}^{*} \\
& K_{17} \\
& +\left(a_{r}-\frac{\alpha c_{t}}{2}+\frac{\left(2 \beta\left(\alpha^{2}-\beta\right)-\alpha(\beta-1)\right) c_{t}+(\alpha(\beta-1)) a_{n}+2\left(\beta^{2}-\alpha^{2}\right) a_{r}}{4 \alpha^{2}-2 \beta(1+\beta)}\right) \\
& K_{18} \\
& \pi_{M}^{I I I}=\left(K_{15} w_{n}^{*}+\left(\frac{\beta}{2}\right) w_{r}^{*}+\left(\frac{\beta}{2}\right) A_{r}^{*}+K_{16}\right) \times\left(w_{n}{ }^{*}-c_{m}\right) \\
& +\left(K_{17} w_{n}^{*}+\left(\frac{-\alpha}{2}\right) w_{r}^{*}+\left(\frac{-\alpha}{2}\right) A_{r}^{*}+K_{18}\right) \times\left(\left(1+\frac{\alpha}{2 \lambda}\right) w_{r}^{*}-A_{r}^{*}-\frac{K_{17} w_{n}^{*}+K_{18}-b}{\lambda}-c_{r}\right)
\end{aligned}
$$


$\pi_{M}{ }^{I I I}$ function is a decreasing function according to $A_{r}{ }^{*}$ in the feasible area, hence the optimal value of $A_{r}{ }^{*}$ is the minimum value that it can achieve. Retailer's profit for returning each product should be at least equal to $R P_{2}$ so the minimum value of $A_{r}{ }^{*}$ is calculated by equation (C. 23).

$A_{r}^{*} \geq R P_{2} \Rightarrow A_{r}^{*}=R P_{2}$

Hence equation (C. 22), is changed as equation (C. 24), and the optimum values of $w_{n}{ }^{*}$ and $w_{r}{ }^{*}$ can be calculated by solving the equalities of the equation (C. 25).

$$
\begin{aligned}
& \pi_{M}^{I I I}=\left(K_{15} w_{n}^{*}+\left(\frac{\beta}{2}\right) w_{r}^{*}+\left(\frac{\beta}{2}\right) R P_{2}+K_{16}\right) \times\left(w_{n}^{*}-c_{m}\right) \\
& +\left(K_{17} w_{n}{ }^{*}+\left(\frac{-\alpha}{2}\right) w_{r}{ }^{*}+\left(\frac{-\alpha}{2}\right) R P_{2}+K_{18}\right) \times\left(\left(1+\frac{\alpha}{2 \lambda}\right) w_{r}{ }^{*}-R P_{2}-\frac{K_{17} w_{n}{ }^{*}+K_{18}-b}{\lambda}-c_{r}\right)
\end{aligned}
$$

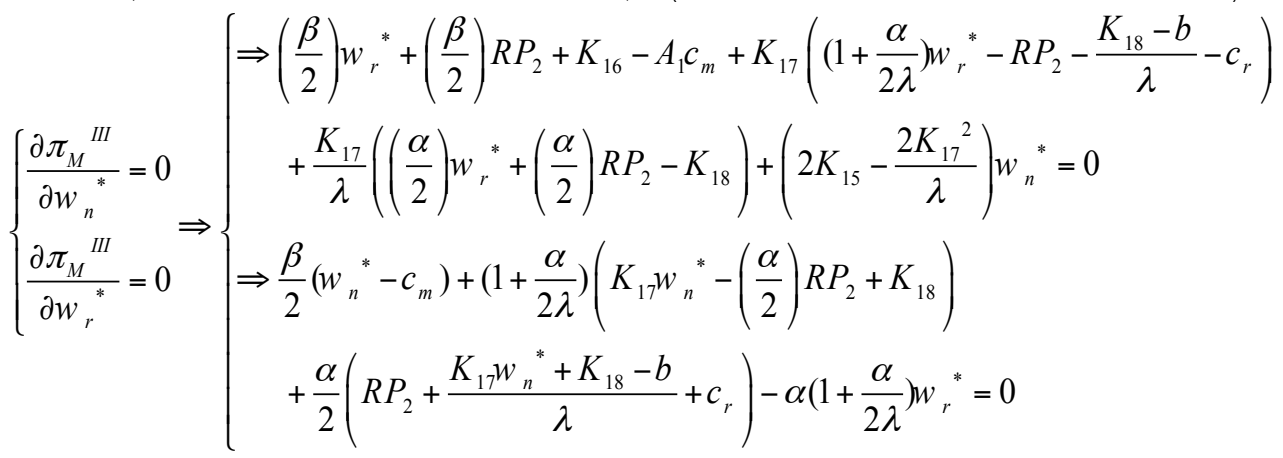

The formulations of $K_{i}$ are presented by equations (C. 26) to (C. 34).

$$
\begin{aligned}
& K_{19}=\frac{\beta^{2}-\alpha^{2}}{\alpha} R P_{1}-\frac{\beta}{2} R P_{2}+a_{n}+\frac{\beta^{2}-2 \alpha^{2}}{2 \alpha} c_{t}+\frac{\beta}{2}\left(\frac{a_{r}}{\alpha}+c_{r}\right) \\
& K_{20}=\frac{\alpha}{2} R P_{2}+\frac{a_{r}-\alpha c_{r}+\beta c_{t}}{2} \\
& K_{21}=\frac{b}{\lambda}-\left(1+\frac{\alpha}{2 \lambda}\right) R P_{2}-c_{r}-\frac{a_{r}-\alpha c_{r}+\beta c_{t}}{2} \\
& K_{22}=\frac{a_{n}+(\beta-\alpha) c_{t}}{2}-\frac{\beta}{2} R P_{2} \\
& K_{23}=\frac{b}{\lambda}-\left(1+\frac{\beta^{2}}{2 \alpha \lambda}\right) R P_{2}-c_{r}-\frac{\frac{\beta^{2}-\alpha^{2}}{\alpha}\left(R P_{1}+c_{t}\right)+\frac{\beta(\alpha-\beta)}{2 \alpha} c_{t}+\frac{\beta a_{n}}{2 \alpha}}{\lambda} \\
& K_{24}=a_{r}+\frac{\beta^{2} R P_{2}+2\left(\beta^{2}-\alpha^{2}\right)\left(R P_{1}+c_{t}\right)+\beta\left((\alpha-\beta) c_{t}+a_{n}\right)}{2 \alpha} \\
& K_{25}=a_{n}+\left(R P_{1}+c_{t}\right)(\beta-\alpha) \\
& K_{26}=a_{r}+\left(R P_{1}+c_{t}\right)(\beta-\alpha) \\
& K_{27}=\frac{b}{\lambda}-R P_{2}-c_{r}-\frac{a_{r}+(\beta-\alpha)\left(R P_{1}+c_{t}\right)}{\lambda}
\end{aligned}
$$




\section{The Fourth Structure}

Equations (C. 35) and (C. 36), show the first-order derivatives of $\pi_{M}{ }^{I V}$, and $\pi_{R M}{ }^{I V}$. Please note that $A_{c}{ }^{*}$, has been determined previously by using Theorem 1 .

$$
\begin{aligned}
& \frac{\partial \pi_{M}{ }^{I V}\left(p_{n}\right)}{\partial p_{n}}=a_{n}+\beta p_{r}+\alpha\left(c_{m}+c_{t}\right)-2 \alpha p_{n} \\
& \frac{\partial \pi_{R M}{ }^{I V}\left(p_{r}{ }^{*}, A_{c}{ }^{*}\right)}{\partial p_{r}{ }^{*}}=\left(\beta+\frac{2 \alpha \beta}{\lambda}\right) p_{n}{ }^{*}+\left(1+\frac{2 \alpha}{\lambda}\right) a_{r}+\alpha\left(c_{r}+c_{t}-\frac{b}{\lambda}\right)-2 \alpha\left(1+\frac{\alpha}{\lambda}\right) p_{r}{ }^{*}
\end{aligned}
$$

\subsection{Nash equilibrium}

The Nash equilibrium can be determined by equalities of equation (C. 37). By solving equation (C. 37), the Nash equilibrium will be determined as equations (C. 38) and (C. 39).

$$
\begin{aligned}
& \int \frac{\partial \pi_{M}{ }^{I}}{\partial p_{n}}=0 \Rightarrow p_{n}{ }^{*}=\frac{a_{n}+\beta p_{r}{ }^{*}+\alpha\left(c_{m}+c_{t}\right)}{2 \alpha} \\
& \left\{\frac{\partial \pi_{R M}{ }^{I V}}{\partial p_{r}{ }^{*}}=0 \Rightarrow p_{r}{ }^{*}=\frac{\left(\beta+\frac{2 \alpha \beta}{\lambda}\right) p_{n}{ }^{*}+\left(1+\frac{2 \alpha}{\lambda}\right) a_{r}+\alpha\left(c_{r}+c_{t}-\frac{b}{\lambda}\right)}{2 \alpha\left(1+\frac{\alpha}{\lambda}\right)}\right. \\
& p_{n}^{*}=\frac{a_{n}+\alpha\left(c_{m}+c_{t}\right)}{2 \alpha}+\frac{\left(\beta+\frac{2 \alpha \beta}{\lambda}\right)\left(\frac{a_{n}+\alpha\left(c_{m}+c_{t}\right)}{2 \alpha}\right)+\left(1+\frac{2 \alpha}{\lambda}\right) a_{r}+\alpha\left(c_{r}+c_{t}-\frac{b}{\lambda}\right)}{\frac{4 \alpha^{2}}{\beta}\left(1+\frac{\alpha}{\lambda}\right)-2 \alpha \beta\left(\frac{1}{2 \alpha}+\frac{1}{\lambda}\right)} \\
& p_{r}{ }^{*}=\frac{\left(\beta+\frac{2 \alpha \beta}{\lambda}\right)\left(\frac{a_{n}+\alpha\left(c_{m}+c_{t}\right)}{2 \alpha}\right)+\left(1+\frac{2 \alpha}{\lambda}\right) a_{r}+\alpha\left(c_{r}+c_{t}-\frac{b}{\lambda}\right)}{2 \alpha\left(1+\frac{\alpha}{\lambda}\right)-\beta^{2}\left(\frac{1}{2 \alpha}+\frac{1}{\lambda}\right)}
\end{aligned}
$$

\subsection{Manufacturer leader}

The remanufacturer's best response $\left(p_{r}{ }^{*}\left(p_{n}{ }^{*}\right)\right)$ can be calculated by the first-order derivative of his profit function as equation (C. 40$)$ shows. Similarly, the manufacturer's best decision $\left(p_{n}{ }^{*}\right)$ can be calculated by the first-order derivative of his profit function as equation (C. 41) shows.

$$
\frac{\partial \pi_{R M}{ }^{I}}{\partial p_{r}{ }^{*}}=0 \Rightarrow p_{r}{ }^{*}\left(p_{n}{ }^{*}\right)=\frac{\left(\beta+\frac{2 \alpha \beta}{\lambda}\right) p_{n}{ }^{*}+\left(1+\frac{2 \alpha}{\lambda}\right) a_{r}+\alpha\left(c_{r}+c_{t}-\frac{b}{\lambda}\right)}{2 \alpha\left(1+\frac{\alpha}{\lambda}\right)}
$$




$$
\frac{\partial \pi_{M}{ }^{I V}}{\partial p_{n}{ }^{*}}=0 \Rightarrow p_{n}{ }^{*}=\frac{2 \alpha a_{n}\left(1+\frac{\alpha}{\lambda}\right)+\beta a_{r}\left(1+\frac{2 \alpha}{\lambda}\right)+\alpha\left(c_{r}+c_{t}-\frac{b}{\lambda}\right)-\left(\beta^{2}+\frac{2 \alpha \beta^{2}}{\lambda}\right)\left(c_{m}+c_{t}\right)}{4 \alpha^{2}\left(1+\frac{\alpha}{\lambda}\right)-\left(\beta^{2}+\frac{2 \alpha \beta^{2}}{\lambda}\right)}
$$

\subsection{Remanufacturer leader}

The manufacturer's best response $\left(p_{n}{ }^{*}\left(p_{r}{ }^{*}\right)\right)$ is calculated by the first-order derivative of his profit function as equation (C. 42). And the optimal vale of $p_{r}{ }^{*}$ is determined by equation (C.

43) similar to the prior models.

$$
\begin{aligned}
& \frac{\partial \pi_{M}{ }^{I V}}{\partial p_{n}}=0 \Rightarrow p_{n}{ }^{*}\left(p_{r}{ }^{*}\right)=\frac{a_{n}+\beta p_{r}{ }^{*}+\alpha\left(c_{m}+c_{t}\right)}{2 \alpha} \\
& \frac{\partial \pi_{R M}{ }^{I V}}{\partial p_{r}{ }^{*}}=0 \Rightarrow p_{r}{ }^{*}=\frac{\left(\begin{array}{l}
\frac{\beta^{2}-2 \alpha^{2}}{2 \alpha}\left(\frac{a_{r}-b}{\lambda}+\frac{\beta a_{n}+\alpha \beta\left(c_{m}+c_{t}\right)}{2 \alpha \lambda}+c_{r}+c_{t}\right) \\
-\frac{2 \alpha \lambda+2 \alpha^{2}-\beta^{2}}{2 \alpha \lambda}\left(a_{r}+\frac{\beta a_{n}+\alpha \beta\left(c_{m}+c_{t}\right)}{2 \alpha}\right)
\end{array}\right)}{\left(\frac{\left(\beta^{2}-2 \alpha^{2}\right)\left(2 \alpha \lambda+2 \alpha^{2}-\beta^{2}\right)}{\alpha^{2} \lambda}\right)}
\end{aligned}
$$

